\title{
Pharmacogenetics of hepatocellular carcinoma and cholangiocarcinoma
}

\author{
Marta Alonso-Peña', Anabel Sanchez-Martin', Paula Sanchon-Sanchez', Meraris Soto-Muñiz', Ricardo \\ Espinosa-Escudero', Jose J.G. Marin ${ }^{1,2}$
}

'Experimental Hepatology and Drug Targeting (HEVEFARM), IBSAL, University of Salamanca, Salamanca 37007, Spain. ${ }^{2}$ Center for the Study of Liver and Gastrointestinal Diseases (CIBERehd). Carlos III National Institute of Health, Madrid 28029, Spain.

Correspondence to: Prof. Jose J.G. Marin, Department of Physiology and Pharmacology, Campus Miguel de Unamuno E.I.D. S-09, Salamanca 37007, Spain. E-mail: jjgmarin@usal.es

How to cite this article: Alonso-Peña M, Sanchez-Martin A, Sanchon-Sanchez P, Soto-Muñiz M, Espinosa-Escudero R, Marin JJG. Pharmacogenetics of hepatocellular carcinoma and cholangiocarcinoma. Cancer Drug Resist 2019;2:680-709. http://dx.doi.org/10.20517/cdr.2019.006

Received: 22 Jan 2019 First Decision: 26 Feb 2019 Revised: 18 May 2019 Accepted: 3 Jun 2019 Published: 19 Sep 2019

Science Editor: Godefridus J. Peters Copy Editor: Cai-Hong Wang Production Editor: Jing Yu

\begin{abstract}
Primary liver cancers constitute the fourth most deadly group of cancers. Their poor prognosis is due in part to the pre-existence and/or development, often during treatment, of powerful mechanisms accounting for the poor response of cancer cells to antitumor drugs. These include both impaired gene expression and the appearance of spliced variants, polymorphisms and mutations, affecting the function of genes leading to the reduction in intracellular concentrations of active agents, changes in molecular targets and survival pathways, altered tumor microenvironment and phenotypic transition. The present review summarizes available information regarding the role of germline and somatic mutations affecting drug transporters, enzymes involved in drug metabolism, organelles and signaling molecules related to liver cancer chemoresistance. A more complete picture of the actual complexity of this problem is urgently needed for carrying out further pharmacogenomic studies aimed to improve the management of patients suffering from hepatocellular carcinoma or cholangiocarcinoma.
\end{abstract}

Keywords: Anticancer drug, chemoresistance, chemotherapy, cholangiocarcinoma, germline mutation, hepatoma, liver cancer, somatic mutation

\section{INTRODUCTION}

Primary liver cancers (PLCs) are an important proportion of total malignant neoplasias, constituting the fourth cause of cancer-related death worldwide. According to data from Global Cancer Observatory, there

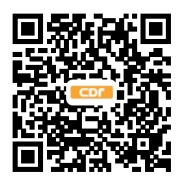


are more than 840,000 new cases of PLCs diagnosed each year and, due to their late diagnosis and poor prognosis, this is accompanied by high mortality, which accounts for approximately $8 \%$ of deaths due to cancer.

The most frequent PLC is hepatocellular carcinoma (HCC). This is usually diagnosed by imaging techniques and determination of serum tumor markers, mainly alpha-fetoprotein, followed by confirmatory histological study of the biopsy ${ }^{[1]}$. HCC etiopathogenetic is often difficult to define, with different potentially involved factors, such as genetic alterations (chromosomal and gene mutations), epigenetic changes, and risk factors like cirrhosis, metabolic diseases such as NASH, dietary aflatoxin B1 in Asian countries or viral hepatitis ${ }^{[2-4]}$. The best curative option for early stages is surgical resection, liver transplant or radiofrequency ablation. Unfortunately, HCC is often diagnosed at intermediate or advanced stages. For these patients, the first-line treatment is transarterial chemoembolization (TACE) in the intermediate stage and systemic chemotherapy in the case of advanced $\mathrm{HCC}^{[1,5]}$. The response to conventional chemotherapeutic agents, for instance cisplatin, interferon, 5-fluorouracil and doxorubicin in the so-called PIAF regimen, is often very poor due to intrinsic or acquired chemoresistance. Among new targeted drugs, sorafenib, an inhibitor of several tyrosine kinase receptors (TKR), is currently used as the first-line treatment in patients with advanced $\mathrm{HCC}^{[6]}$. Nevertheless, the benefit in terms of median overall survival (OS) is only of 2.8 month ${ }^{[2,5,6]}$. Regorafenib, another tyrosine kinase inhibitor (TKI) also approved by FDA, has a similar effect to sorafenib and is now being used as a second-line treatment for patients who cannot tolerate sorafenib treatment or undergo tumor progression during sorafenib therapy ${ }^{[7]}$. Recently, other TKIs have been approved for being used against advanced HCC resistant to sorafenib, such as nivolumab, cabozantinib and lenvatinib ${ }^{[8]}$.

Cholangiocarcinoma (CCA), the second most frequent type of PLC (10\%-15\% of all PLCs) is a heterogeneous group of malignancies derived from the biliary epithelium. Depending on the anatomical location, CCA is classified into intrahepatic (iCCA), perihilar (pCCA) and distal (dCCA) types. CCA etiopathogenesis has been associated with certain risk factors, such as advanced age, obesity, alcohol consumption, chronic biliary diseases (e.g., primary sclerosing cholangitis and liver cirrhosis), chronic infection by liver flukes (e.g., Clonorchis sinensis and Opisthorchis viverrini), viral hepatitis, congenital diseases (e.g., Caroli disease), drugs or chemicals (e.g., smoking, thorotrast and dioxin). The diagnosis of CCA is usually based on the combination of imaging techniques, because specific histological and serum biochemical markers are still under investigation ${ }^{[9,10]}$. Surgical resection is the best curative therapy for CCA but this option is only possible in a few cases. For the rest of CCA patients with unresectable or metastatic cancer, conventional systemic chemotherapy (gemcitabine combined with cisplatin as first-line treatment or gemcitabine alone) or locoregional therapy, such as TACE, transarterial radioembolization or radiofrequency ablation, could be an alternative. The use of targeted therapies based on either TKIs, such as erlotinib and lapatinib, or antibodies, such as bevacizumab, cetuximab, and panitimumab has resulted of little benefit ${ }^{[1]}$.

Despite the efforts in the development of novel treatments to improve PLCs outcome, advances have been modest. One of the most important challenges in PLC pharmacology is to overcome the poor response of these tumors to anticancer drugs, which is due in part to powerful mechanisms of chemoresistance (MOC). These include not only impaired gene expression, but also the existence of genetic variants affecting the function of proteins involved in MOC. Lower intracellular levels of active agents can be mediated by changes in the transportome resulting in impaired drug uptake (MOC-1a), enhanced drug export (MOC-1b), or alterations in drug metabolism that could lead to impaired prodrug activation or increased proportion of inactive metabolites (MOC-2). Additionally, alterations in: i) target genes of antitumor drugs, ii) the activity of mechanisms involved in DNA repair and iii) unbalance between survival and apoptosis factors, are involved in chemoresistance. These processes are classified into MOC-3, MOC-4 and MOC-5, respectively. Finally, the role of changes related to tumor environment (MOC-6) and epithelial-mesenchymal transition (EMT, MOC-7) in PLC chemoresistance is still poorly understood [Figure 1] $]^{[12]}$. 


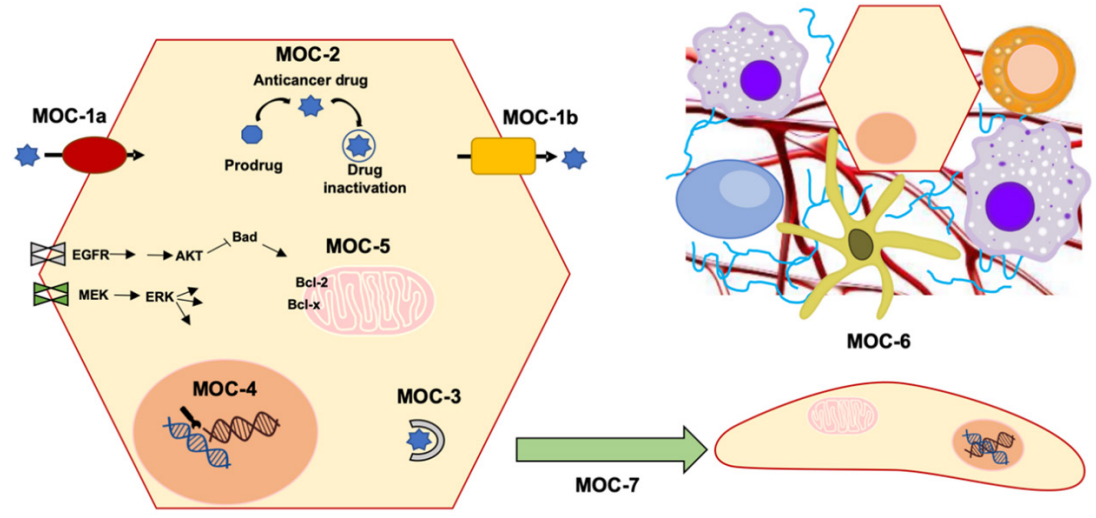

Figure 1. Scheme of mechanisms of chemoresistance (MOC): reduction in intracellular concentration of active drugs (MOC-1 and MOC-2), changes in molecular targets (MOC-3), enhanced DNA repair mechanisms (MOC-4), altered balance between survival and apoptosis pathways (MOC-5), tumor microenvironment (MOC-6) and epithelial-mesenchymal transition (MOC-7)
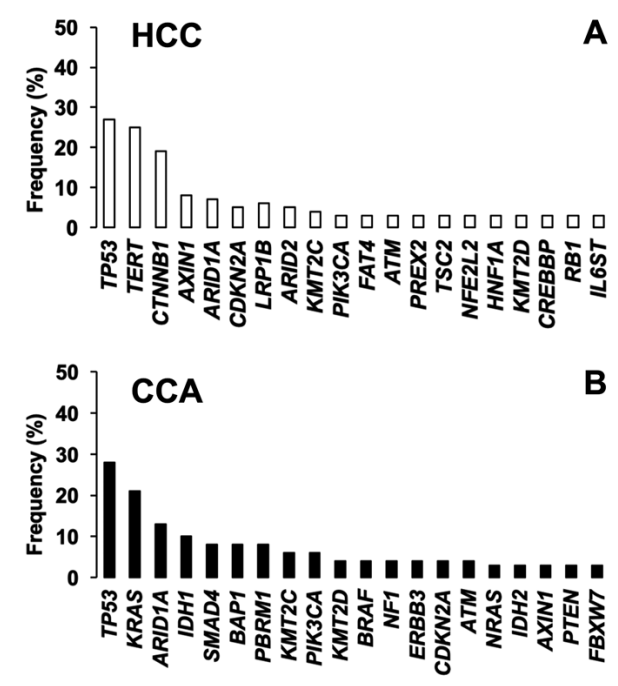

Figure 2. Top 20 most frequently mutated genes in A: hepatocellular carcinoma (HCC); and B: cholangiocarcinoma (CCA). Adapted from COSMIC database (https://cancer.sanger.ac.uk/cosmic)

Given the complexity and heterogeneity of PLCs, the use of personalized diagnosis based on the analysis of genetic variants is becoming an urgent need to establish an optimized treatment for each patient. Therefore, the clinical relevance of pharmacogenetic studies is increasing. The mutational signature has identified the main genes with the most relevant alterations both in HCC and CCA. This includes oncogenes and tumor suppressor genes involved in signaling pathways related to survival, proliferation, differentiation and DNA repair [Figure 2]. In this review, we have summarized current knowledge regarding mutations identified in HCC and CCA, and their role in multidrug resistance (MDR) phenotype and patient outcome. We have distinguished between somatic mutation, i.e., acquired by tumor cells during carcinogenesis, and germline mutations, i.e., inherited genetic alterations. For the nomenclature of the mutations that appear in this review, the updated recommendations of the Sequence Variant Description Working Group ${ }^{[13]}$, which operates under the auspices of three international organizations: the Human Genome Variation Society, the Human Varioma Project and the Human Genome Organization (HUGO), have been followed. Singlenucleotide polymorphisms (SNP) have been considered substitutions of a single nucleotide that occur within a population with a frequency higher than $1 \%$, whereas a single-nucleotide variant, without any limitations of frequency, that may arise in cancer cells is called a single-nucleotide alteration (SNA). 


\section{CHANGES IN INTRACELLULAR CONCENTRATIONS OF ACTIVE ANTICANCER AGENTS}

Many anticancer drugs perform their therapeutic action inside tumor cells. For this reason, mechanisms reducing their intracellular concentrations impair the effectiveness of the treatment. In this sense, changes in the activity of transporters accounting for drug uptake or efflux could determine the capability of anticancer drugs to reach their molecular targets. Moreover, some drugs are administered as prodrugs, which means that they need to be metabolized intracellularly to generate active compounds. In contrast, other drugs are rapidly biotransformed into inactive metabolites. Thus, changes in the expression and activity of drugmetabolizing enzymes can determine the overall response to chemotherapy.

\section{Mutations affecting the transportome (MOC-1)}

Two main superfamilies of transporters are involved in MOC-1: Solute carrier (SLC) proteins and ATPbinding cassette $(\mathrm{ABC})$ proteins. Members of the first group are involved in the uptake of a wide range of molecules, while several ABC pumps use the energy released by the ATP hydrolysis to export their substrates from the cells.

Genetic variants in genes involved in drug uptake (MOC-1a)

Among drug uptake transporters, those encoded by SLCO, SLC22A and SLC31A gene families have been extensively described as main players in the transport of anticancer drugs used against HCC and CCA, such as platinum derivatives and TKIs. Moreover, SLC28A and SLC29A gene families, which encode transporters able to carry out concentrative (CNT) and equilibrative (ENT) nucleoside uptake, are involved in the response to nucleoside and pyrimidine base analogs, such as gemcitabine and 5- $\mathrm{FU}^{[14]}$. Accordingly, mutations affecting these genes could modify the response of HCC and CCA to their substrates. Until now, most investigations have been focused on the association between gene expression and drug resistance. There is also information on the role of germline mutations in antitumor drug pharmacokinetics. In contrast, there is only a few studies regarding somatic mutations affecting SLC transporters in HCC and CCA. Available information can be obtained from COSMIC (https://cancer.sanger.ac.uk/cosmic) and TCGA (https://cancergenome.nih. gov/) databases. Table 1 provides a summary of mutations affecting SLCO, SLC22A, SLC28A, SLC29A and SLC31 A genes in HCC and CCA.

Germline pharmacogenetics: Among the members of SLCO gene family, OATP1B1 (SLCO1B1) and OATP1B3 (SLCO1B3), which have redundant substrate specificity, have been characterized as transporters of TKIs, including sorafenib ${ }^{[15]}$. Several in vivo and in vitro studies have described SNPs or haplotypes that result in altered expression, localization and activity of OATPs. Most research has been focused on germline polymorphisms of $\mathrm{OATP} 1 \mathrm{~B} 1$ and $\mathrm{OATP} 1 \mathrm{~B} 3$ affecting pharmacokinetics and response of statins and paclitaxel, respectively ${ }^{[16]}$. Two germline mutations in $\mathrm{OATP} 1 \mathrm{~B} 1, \mathrm{c} .388 \mathrm{~A}>\mathrm{G}$ (p.Asn130Asp) and c.521T>C (p.Val174Ala), have been associated with side effects after treatment of HCC patients with sorafenib. However, none of the investigated polymorphisms has been associated with the survival of these patients ${ }^{[17]}$. In patients with unresectable liver metastasis from colorectal cancer, genetic variants of OATP1B3 (c.334T>G; p.Ser112Ala and c.699G>A; p.Met233Ile) and OCT1 (SLC22A1, c.1260_1262delGAT; p.Met420del) have been linked to neutropenia and diarrhea, respectively, when they were treated with hepatic artery infusion of irinotecan, oxaliplatin and 5-FU, and intravenous cetuximab ${ }^{[18]}$. Several OCT3 $(S L C 22 A 3)$ variants have been studied, but none of them have been related neither to HCC nor to $\mathrm{CCA}^{[19,20]}$.

On the other hand, germline mutations in SLC28A and SLC29A genes affecting gemcitabine effectiveness have been identified in breast cancer ${ }^{[21]}$ and non-small-cell lung cancer ${ }^{[22,23]}$. Unfortunately, there are no similar studies in PLCs.

CTR1 (SLC31A1) is a copper transporter involved in the uptake of platinum derivatives. The study of the relationship between CTR1 polymorphisms and the response of CCA to the therapy with gemcitabine plus 
Table 1. Germline (G) and somatic (S) mutations affecting coding (c) and non-coding (nc) regions of SLC genes in primary liver cancer

\begin{tabular}{|c|c|c|c|c|c|c|c|c|c|}
\hline Gene & Protein & $\begin{array}{c}\text { Genetic } \\
\text { mutations }\end{array}$ & $\mathbf{G} / \mathbf{S}$ & Region & $\begin{array}{c}\text { Protein } \\
\text { mutations }\end{array}$ & $\begin{array}{c}\text { Functional } \\
\text { consequence }\end{array}$ & Clinical consequences & Studies & References \\
\hline \multirow[t]{4}{*}{ SLCO1B1 } & OATP1B1 & c.521T>C & G & c & Val174Ala & ND & Thrombocytopenia & HCC patients & {$[17]$} \\
\hline & & c. $388 \mathrm{~A}>\mathrm{G}$ & G & c & Asn130Asp & ND & Diarrhea & HCC patients & [17] \\
\hline & & c.1039T>G & $\mathrm{S}$ & c & Leu347Val & Moderate & ND & TCGA-LIHC & TCGA \\
\hline & & c. $152 C>A$ & S & c & Ser51Tyr & Moderate & Pathogenic & TCGA-LIHC & TCGA \\
\hline \multirow[t]{6}{*}{ SLCO1B3 } & OATP1B3 & c. $334 \mathrm{~T}>\mathrm{G}$ & G & c & Ser112Ala & ND & Neutropenia & $\begin{array}{l}\text { Unresectable } \\
\text { liver metastasis }\end{array}$ & {$[18]$} \\
\hline & & c. $699 \mathrm{G}>\mathrm{A}$ & G & c & Met233Ile & ND & Neutropenia & $\begin{array}{l}\text { Unresectable } \\
\text { liver metastasis }\end{array}$ & {$[18]$} \\
\hline & & c. $391 C>A$ & S & c & Pro131Thr & Moderate & ND & TCGA-LIHC & TCGA \\
\hline & & $c .10 C>A$ & S & c & His4Asn & Moderate & ND & TCGA-LIHC & TCGA \\
\hline & & c. $166 \mathrm{G}>\mathrm{A}$ & S & $c$ & Glu56Lys & Moderate & Pathogenic & TCGA-LIHC & TCGA \\
\hline & & c. ${ }^{\star} 12 T>C$ & $\mathrm{~S}$ & $\mathrm{nc}$ & $3^{\prime}$ UTR & Modifier & ND & TCGA-LIHC & TCGA \\
\hline \multirow[t]{7}{*}{ SLC22A1 } & OCT1 & c.1260delGAT & G & c & Met420del & High & Diarrhea & $\begin{array}{l}\text { Unresectable } \\
\text { liver metastasis }\end{array}$ & {$[18]$} \\
\hline & & c. $262 \mathrm{~T}>\mathrm{C}$ & S & c & Cys88Arg & Moderate & $\begin{array}{l}\text { Lower sorafenib } \\
\text { transport }\end{array}$ & $\begin{array}{l}\mathrm{HCC} \text { and CCA } \\
\text { patients }\end{array}$ & [24] \\
\hline & & c. $566 C>T$ & S & c & Ser189Leu & Moderate & $\begin{array}{l}\text { Lower sorafenib } \\
\text { transport }\end{array}$ & $\begin{array}{l}\mathrm{HCC} \text { and } \mathrm{CCA} \\
\text { patients }\end{array}$ & [24] \\
\hline & & c. $659 \mathrm{G}>\mathrm{T}$ & S & c & Gly220Val & Moderate & $\begin{array}{l}\text { Lower sorafenib } \\
\text { transport }\end{array}$ & $\begin{array}{l}\mathrm{HCC} \text { and } \mathrm{CCA} \\
\text { patients }\end{array}$ & {$[24]$} \\
\hline & & c. $859 C>G$ & $S$ & c & Arg287Gly & Moderate & $\begin{array}{l}\text { Lower sorafenib } \\
\text { transport }\end{array}$ & $\begin{array}{l}\mathrm{HCC} \text { and } \mathrm{CCA} \\
\text { patients }\end{array}$ & [24] \\
\hline & & c.262delT & S & c & $\begin{array}{l}\text { Cys } 88 \text { Ala } \\
\mathrm{fs}^{\star} 16\end{array}$ & High & $\begin{array}{l}\text { Lower sorafenib } \\
\text { transport }\end{array}$ & $\begin{array}{l}\mathrm{HCC} \text { and } \mathrm{CCA} \\
\text { patients }\end{array}$ & [24] \\
\hline & & c.181delCGinsT & S & c & $\begin{array}{l}\text { Arg61Ser } \\
\mathrm{fs}^{\star} 10\end{array}$ & High & $\begin{array}{l}\text { Lower sorafenib } \\
\text { transport }\end{array}$ & $\begin{array}{l}\mathrm{HCC} \text { and } \mathrm{CCA} \\
\text { patients }\end{array}$ & [24] \\
\hline SLC22A2 & Ост2 & c. $470 A>G$ & S & c & Asn157Ser & Moderate & ND & TCGA-LIHC & TCGA \\
\hline SLC22A3 & ост3 & c. $442 \mathrm{~T}>\mathrm{A}$ & S & c & Cys148Ser & Moderate & ND & TCGA-LIHC & TCGA \\
\hline SLC22A4 & OCTN1 & c. ${ }^{\star} 34 \mathrm{C}>\mathrm{A}$ & S & $\mathrm{nc}$ & 3' UTR & Modifier & ND & TCGA-LIHC & TCGA \\
\hline \multirow[t]{3}{*}{ SLC22A5 } & OCTN2 & c. $765 C>G$ & S & c & Asp255Glu & Moderate & ND & TCGA-LIHC & TCGA \\
\hline & & c. $680 \mathrm{G}>\mathrm{A}$ & S & c & Arg227His & Moderate & Pathogenic & TCGA-LIHC & TCGA \\
\hline & & c.1564G >A & S & c & Asp522Asn & Moderate & ND & TCGA-CHOL & TCGA \\
\hline \multirow[t]{2}{*}{ SLC28A1 } & CNT1 & c. $461+367 T>A$ & S & $\mathrm{nc}$ & Intron & Modifier & ND & TCGA-LIHC & TCGA \\
\hline & & c. $461+452 G>T$ & S & $\mathrm{nc}$ & Intron & Modifier & ND & TCGA-LIHC & TCGA \\
\hline \multirow[t]{2}{*}{ SLC28A3 } & CNT3 & c.1105T>C & S & c & Ser369Pro & Moderate & Pathogenic & TCGA-LIHC & TCGA \\
\hline & & c. $-26 C>T$ & S & $\mathrm{nc}$ & $5^{\prime}$ UTR & Modifier & ND & TCGA-LIHC & TCGA \\
\hline SLC29A1 & ENT1 & c. $149 C>A$ & S & c & Ser50Tyr & Moderate & ND & TCGA-LIHC & TCGA \\
\hline \multirow[t]{2}{*}{ SLC29A2 } & ENT2 & c. $658 \mathrm{C}>\mathrm{T}$ & S & c & Arg220Cys & Moderate & Pathogenic & TCGA-LIHC & TCGA \\
\hline & & c. $-143 T>A$ & S & $\mathrm{nc}$ & $5^{\prime}$ UTR & Modifier & ND & TCGA-LIHC & TCGA \\
\hline SLC29A3 & ENT3 & c. $548 \mathrm{G}>\mathrm{C}$ & $\mathrm{S}$ & c & Ser183Thr & Modifier & ND & TCGA-LIHC & TCGA \\
\hline SLC31A1 & CTR1 & c. $-35-14361 C>A$ & G & $\mathrm{nc}$ & Intron & ND & $\begin{array}{l}\text { Response to } \\
\text { gemcitabine plus } \\
\text { platinum treatment }\end{array}$ & $\begin{array}{l}\text { CCA and } \\
\text { gallbladder } \\
\text { cancer patients }\end{array}$ & {$[25]$} \\
\hline
\end{tabular}

Data obtained from referred literature and TCGA database. Functional consequences are based on VEP (Variant Effect Predictor; https://www.ensembl.org/vep) impact: High means that the variant is supposed to cause a high disruptive impact on the protein, which is likely to cause loss of function; Moderate means that the variant may be not disruptive, but results in a decrease effectiveness of the encoded protein; Modifier is usually referred to non-coding variants, whose impact is difficult to determine, although they can be involved in transcription or splicing changes. CCA: cholangiocarcinoma; HCC: hepatocellular carcinoma; ND: not described; TCGA: the cancer genome atlas; TCGA-LIHC: the cancer genome atlas - liver hepatocellular carcinoma; TCGA-CHOL: the cancer genome atlas cholangiocarcinoma

platinum did not reveal a clear association between SNPs and the treatment outcome, which could be due to the advanced stage of the disease in patients included in the cohort ${ }^{[25]}$. In contrast, the same study proposed that the combination of SLC31A1 c.-35-14361C>A with other SNP in ERCC1 (see below) could be a good predictor of the response to gemcitabine plus platinum treatment ${ }^{[25]}$. Furthermore, a significant relationship between two SLC31A1 intron variants, platinum resistance and clinical outcome has been described in Chinese non-small-cell lung carcinoma patients ${ }^{[26]}$. 
Somatic pharmacogenetics: Although downregulation of OATP1B1 and OATP1B3 in HCC, CCA and advanced metastatic liver tumors has been reported ${ }^{[27]}$, no information on somatic mutations affecting these transporters in PLCs is available. Regarding SLC22A genes, several variants of OCT1 have been identified in PLCs, including SNAs and splicing variants ${ }^{[24]}$. Among them, several inactivating variants, such as c. $262 \mathrm{~T}>\mathrm{C}$ (p.Cys88Arg), c.566C $>\mathrm{T}$ (p.Ser189Leu), c.659G >T (p.Gly220Val) and c.859C >G (p.Arg287Gly), were detected with a higher frequency in HCC and CCA than in the adjacent non-tumor tissue. In vitro studies showed that these and other OCT1 mutations found in PLCs, such as c.262delT (p.Cys88Alafs*16) and c.181delCGinsT (p.Arg61Serfs ${ }^{\star} 10$ ), result in lower sorafenib uptake and hence poorer induced cytotoxicity. Short non-functional SLC22A1 mRNA variants have also been detected in other malignancies, such as glioma $^{[28]}$ and chronic myeloid ${ }^{[29-31]}$ and lymphocytic ${ }^{[32]}$ leukemia. Moreover, not only mRNA abundance but also the correct localization of OCT1 at the plasma membrane is important for the response of HCC patients to sorafenib ${ }^{[33]}$. The reduction in $S L C 22 A 1$ expression has been associated with advanced tumor stages and shorter survival of patients with $\mathrm{HCC}^{[34]}$ or $\mathrm{CCA}^{[35]}$.

Evidence for reduced ОСТз expression in HCC and CCA has also been found. In vitro experiments in cisplatin resistant hepatoma cells have shown reduced OCT3 expression in these cells, which resulted in lower cisplatin uptake, whereas induced OCT3 overexpression restored the sensitivity of these cells to cisplatin $^{[36]}$. Whether, in addition to changes in transcription, there are associated somatic mutations is not known.

Some studies have described a correlation between low SLC29A1 expression and poor prognosis in HCC patient $^{[37]}$, whereas up-regulation of SLC29A2 has been associated with advanced stages, vascular invasion and poor survival in these patients ${ }^{[38]}$. However, no further research on somatic mutations affecting these transporters has been reported.

\section{Genetic variants in genes involved in drug export (MOC-1b)}

$A B C$ transporters mediate the active efflux of a large variety of compounds, including antitumor drugs. Thus, a high expression/activity of these pumps induces a decrease in intracellular drug concentrations that plays an important role in the MDR phenotype of $\mathrm{PLCs}^{[39]}$. Several mutations affecting these transporters may determine the response of HCC and CCA to their substrates [Table 2].

Germline pharmacogenetics: Concerning germline mutations, only those affecting ABCG2 (c.34G>A; p.Val12Met and the intron variant g.89078924T $>C$ ) deserve to be mentioned. Both in vitro ${ }^{[40]}$ and in vivo ${ }^{[41]}$ studies have demonstrated the ability of the breast cancer resistance protein (BCRP) encoded by ABCG2 to export sorafenib with higher affinity than $\mathrm{MDR}_{1}{ }^{[42]}$. Hence, when present in homozygosis, these mutations have been associated with lower exposure of extratumor tissues and a better response to sorafenib ${ }^{[43]}$.

Somatic pharmacogenetics: MDR1 $(A B C B 1)$ also known as P-glycoprotein, is involved in the pharmacokinetics of many drugs ${ }^{[4]}$, including sorafenib ${ }^{[42]}$, which is consistent with the fact that MDR1 expression has been inversely correlated with HCC response to pharmacological treatment ${ }^{[45,46]}$. Interestingly, MDR1 has been found highly expressed in CCA biopsies ${ }^{[47]}$ and cell lines ${ }^{[48]}$. Regarding its genetic variability, more than 60 SNAs for $A B C B 1$ have been described ${ }^{[49]}$. The presence of the synonymous SNP c.3435C >T (p.Ile1145=) in heterozygous patients has been associated with increased levels of MDR1 and higher risk of HCC recurrence ${ }^{[50]}$. This mutation has also been related to a lower exposure to sorafenib in HCC patients ${ }^{[43,51]}$.

Proteins encoded by $A B C C$ genes, also known as multidrug resistance-associated proteins, are involved in PLC chemoresistance ${ }^{[52-56]}$. The presence of the polymorphism c.-1666G>A in MRP1 $(A B C C 1)$ has been correlated with low promoter transcriptional activity ${ }^{[57]}$. The opposite occurs in the case of the variant c.$260 \mathrm{G}>\mathrm{C}^{[58]}$. Moreover, poor outcome and shorter survival have been described in patients with PLC carrying the $\mathrm{c} .-1666 \mathrm{G}>\mathrm{A}$ variant ${ }^{[57]}$. 
Table 2. Germline (G) and somatic (S) mutations affecting coding (c) and non-coding (nc) regions of ABC genes in primary liver cancer

\begin{tabular}{|c|c|c|c|c|c|c|c|c|c|}
\hline Gene & Protein & Genetic mutations & G/S & Region & Protein mutations & $\begin{array}{c}\text { Functional } \\
\text { consequences }\end{array}$ & $\begin{array}{c}\text { Clinical } \\
\text { consequences }\end{array}$ & Studies & References \\
\hline \multirow[t]{9}{*}{$\mathrm{ABCB} 1$} & MDR1 & c.1537A>T & $\mathrm{S}$ & c & Ile513Phe & Moderate & ND & TCGA-LIHC & TCGA \\
\hline & & c. $2621 \mathrm{~T}>\mathrm{C}$ & S & c & Val874Ala & Moderate & ND & TCGA-LIHC & TCGA \\
\hline & & c. $20 \mathrm{G}>\mathrm{A}$ & S & c & Arg7His & Moderate & ND & TCGA-LIHC & TCGA \\
\hline & & c. $246 \mathrm{del} A$ & S & c & Gly 83 Efs $* 3$ & High & ND & TCGA-LIHC & TCGA \\
\hline & & c. $466 \mathrm{~A}>\mathrm{T}$ & S & c & Met156Leu & Moderate & ND & TCGA-LIHC & TCGA \\
\hline & & c. $1827 A>T$ & S & c & Lys609Asn & Moderate & ND & TCGA-LIHC & TCGA \\
\hline & & c. $28887 T>G$ & S & c & Leu963Trp & Moderate & ND & TCGA-LIHC & TCGA \\
\hline & & c.590T>A & S & c & Met197Lys & Moderate & ND & TCGA-LIHC & TCGA \\
\hline & & c. $3435 \mathrm{C}>\mathrm{T}$ & S & c & Ile1145= & ND & $\begin{array}{l}\text { Higher risk of } \\
\text { HCC recurrence }\end{array}$ & $\begin{array}{l}\mathrm{HCC} \\
\text { patients }\end{array}$ & {$[50]$} \\
\hline \multirow[t]{7}{*}{$\mathrm{ABCC} 1$} & MRP1 & c. $2512 A>G$ & S & c & Ile838Val & Moderate & ND & TCGA-LIHC & TCGA \\
\hline & & c. $854 C>A$ & S & c & Pro285GIn & Moderate & ND & TCGA-LIHC & TCGA \\
\hline & & c. $2296 \mathrm{G}>\mathrm{A}$ & S & c & Val766Met & Moderate & ND & $\begin{array}{l}\text { TCGA- } \\
\text { CHOL }\end{array}$ & TCGA \\
\hline & & c. $2281 \mathrm{~A}>\mathrm{T}$ & S & c & Ile761Phe & $\begin{array}{l}\text { Moderate } \\
\text { Moderate }\end{array}$ & ND & TCGA-LIHC & TCGA \\
\hline & & c. $2195 T>A$ & S & $c$ & Leu732GIn & Moderate & ND & TCGA-LIHC & TCGA \\
\hline & & c. $-1666 \mathrm{G}>\mathrm{A}$ & S & $\mathrm{nc}$ & Promoter & ND & Lower expression & $\begin{array}{l}\mathrm{HCC} \\
\text { patients }\end{array}$ & [57] \\
\hline & & c. $-260 G>C$ & S & $\mathrm{nc}$ & Promoter & ND & Higher expression & $\begin{array}{l}\text { HepG2 and } \\
\text { Hep3B cells }\end{array}$ & {$[58]$} \\
\hline \multirow[t]{9}{*}{$\mathrm{ABCC} 2$} & MRP2 & c. $3737 \mathrm{~T}>\mathrm{A}$ & S & c & Leu1246His & Moderate & ND & TCGA-LIHC & TCGA \\
\hline & & c. $71 \mathrm{C}>\mathrm{A}$ & S & c & Pro24Gln & Moderate & ND & $\begin{array}{l}\text { TCGA- } \\
\text { CHOL }\end{array}$ & TCGA \\
\hline & & c. $1781 \mathrm{G}>\mathrm{A}$ & S & c & Ser594Asn & Moderate & ND & TCGA-LIHC & TCGA \\
\hline & & c. $2810 A>G$ & S & c & Asn937Ser & Moderate & ND & TCGA-LIHC & TCGA \\
\hline & & c. $715 \mathrm{G}>\mathrm{T}$ & S & c & Val239Leu & Moderate & ND & TCGA-LIHC & TCGA \\
\hline & & c. $1249 G>A$ & S & c & Val471Ile & ND & Sorafenib efflux & HEK cells & [59] \\
\hline & & c. $3972 C>T$ & $\mathrm{~S}$ & c & Ile1324= & ND & Lower expression & $\begin{array}{l}\text { Patients } \\
\text { with CCA }\end{array}$ & {$[60]$} \\
\hline & & c. $-58 \mathrm{~A}>\mathrm{C}$ & S & $\mathrm{nc}$ & 5' UTR & Modifier & ND & TCGA-LIHC & TCGA \\
\hline & & c. $-24 C>T$ & S & $\mathrm{nc}$ & 5' UTR & ND & Higher expression & $\begin{array}{l}\text { Luciferase } \\
\text { assay }\end{array}$ & {$[61]$} \\
\hline \multirow[t]{10}{*}{$\mathrm{ABCC} 3$} & MRP3 & c.1666_1671dupTACGTG & $S$ & c & Tyr556_Val557 & Moderate & ND & TCGA-LIHC & TCGA \\
\hline & & c. $614 \mathrm{~A}>\mathrm{C}$ & S & c & Asn205Thr & Moderate & ND & TCGA-LIHC & TCGA \\
\hline & & c. $423 \mathrm{G}>\mathrm{T}$ & S & c & Trp141Cys & Moderate & ND & TCGA-LIHC & TCGA \\
\hline & & c. $422 \mathrm{G}>\mathrm{T}$ & S & c & Trp141Leu & Moderate & ND & TCGA-LIHC & TCGA \\
\hline & & c. $800 C>A$ & S & c & Thr267Lys & Moderate & ND & TCGA-LIHC & TCGA \\
\hline & & c.1558G >A & S & c & Gly520Ser & Moderate & ND & TCGA-LIHC & TCGA \\
\hline & & c. $2120 A>G$ & S & c & Glu707Gly & Moderate & ND & TCGA-LIHC & TCGA \\
\hline & & c. $1936 A>C$ & S & c & Ser646Arg & Moderate & ND & TCGA-LIHC & TCGA \\
\hline & & c. $-211 C>T$ & $\mathrm{~S}$ & $\mathrm{nc}$ & 5' UTR & ND & $\begin{array}{l}\text { Lower expression } \\
\text { Same expression }\end{array}$ & $\begin{array}{l}\text { Healthy } \\
\text { liver }\end{array}$ & $\begin{array}{l}{[62]} \\
{[63]}\end{array}$ \\
\hline & & c. ${ }^{\star} 179-9 \_* 179-7$ delTCC & S & $\mathrm{nc}$ & Intron & Modifier & ND & TCGA-LIHC & TCGA \\
\hline \multirow[t]{6}{*}{$\mathrm{ABCC} 4$} & MRP4 & c. $1024 C>A$ & S & c & Leu342Ile & Moderate & ND & TCGA-LIHC & TCGA \\
\hline & & c. $994 \mathrm{G}>\mathrm{A}$ & S & c & Val332Met & Moderate & ND & TCGA-LIHC & TCGA \\
\hline & & c. $382 T>G$ & $\mathrm{~S}$ & c & Ser128Ala & Moderate & ND & TCGA-LIHC & TCGA \\
\hline & & c. $2174 \mathrm{~A}>\mathrm{T}$ & S & c & Gln725Leu & Moderate & ND & TCGA-LIHC & TCGA \\
\hline & & c. $1037 T>A$ & S & c & Ile346Asn & Moderate & ND & TCGA-LIHC & TCGA \\
\hline & & c. $1785 G>C$ & $\mathrm{~S}$ & c & Gln595His & Moderate & ND & TCGA-LIHC & TCGA \\
\hline \multirow[t]{3}{*}{$A B C C 5$} & MRP5 & c. $1745 \mathrm{~A}>\mathrm{T}$ & $\mathrm{S}$ & c & Asp582Val & Moderate & ND & TCGA-LIHC & TCGA \\
\hline & & c. $3724 C>T$ & S & c & Arg1242Cys & Moderate & ND & TCGA-LIHC & TCGA \\
\hline & & c. $4145 T>C$ & $\mathrm{~S}$ & c & Leu1382Phe & Moderate & ND & TCGA-LIHC & TCGA \\
\hline \multirow[t]{2}{*}{$A B C G 2$} & BCRP & c. $34 \mathrm{G}>\mathrm{A}$ & G & c & Val12Met & ND & $\begin{array}{l}\text { Altered sorafenib } \\
\text { pharmacokinetics }\end{array}$ & $\begin{array}{l}\mathrm{HCC} \\
\text { patients }\end{array}$ & {$[43]$} \\
\hline & & g.89078924T >C & G & c & Intron & ND & $\begin{array}{l}\text { Altered sorafenib } \\
\text { pharmacokinetics }\end{array}$ & $\begin{array}{l}\mathrm{HCC} \\
\text { patients }\end{array}$ & [43] \\
\hline
\end{tabular}




\begin{tabular}{|c|c|c|c|c|c|c|c|}
\hline c. $734 C>G$ & $S$ & c & Phe245Arg & Moderate & ND & TCGA-LIHC & TCGA \\
\hline c.1500G>T & $S$ & c & Lys500Asn & Moderate & ND & $\begin{array}{l}\text { TCGA- } \\
\text { CHOL }\end{array}$ & TCGA \\
\hline c. $745 A>G$ & $S$ & $\mathrm{nc}$ & Ile249Val & Moderate & ND & TCGA-LIHC & TCGA \\
\hline g.89073197A>G & $S$ & $\mathrm{nc}$ & Enhancer region & ND & Lower expression & $\begin{array}{l}\text { HepG2 } \\
\text { cells }\end{array}$ & [64] \\
\hline g.88924371A>G & $S$ & $\mathrm{nc}$ & Enhancer region & ND & Lower expression & $\begin{array}{l}\text { HepG2 } \\
\text { cells }\end{array}$ & [64] \\
\hline g.89189602G >A & $S$ & $\mathrm{nc}$ & Enhancer region & ND & Lower expression & $\begin{array}{l}\text { HepG2 } \\
\text { cells }\end{array}$ & [64] \\
\hline ABCG $2 R^{2} 1 * 2$ & $\mathrm{~S}$ & $\mathrm{nc}$ & Enhancer region & ND & Lower expression & $\begin{array}{l}\text { HepG2 } \\
\text { cells }\end{array}$ & [64] \\
\hline g.89026428A>C & $S$ & $\mathrm{nc}$ & Enhancer region & ND & Higher expression & $\begin{array}{l}\text { HepG2 } \\
\text { cells }\end{array}$ & [64] \\
\hline
\end{tabular}

Data obtained from referred literature and TCGA database. Functional consequences are based on VEP (Variant Effect Predictor; https://www.ensembl.org/vep) impact: High means that the variant is supposed to cause a high disruptive impact in the protein, which is likely to cause loss of function; Moderate means that the variant may be not disruptive, but results in a decrease effectiveness of the encoded protein; Modifier is usually referred to non-coding variants, whose impact is difficult to determine, although they can be involved in transcription or splicing changes. CCA: cholangiocarcinoma; HCC: hepatocellular carcinoma; ND: not described; TCGA: the cancer genome atlas; TCGA-LIHC: the cancer genome atlas - liver hepatocellular carcinoma; TCGA-CHOL: the cancer genome atlas cholangiocarcinoma

The best known MRP2 (ABCC2) variants are c.-24C>T, c.1249G>A (p.Val471Ile) and c.3972C >T (p.Ile1324=). These frequent variants have been associated with higher chemoresistance and reduced survival rate in many different tumors, including HCC and $\mathrm{CCA}^{[61,65-67]}$. Some combinations of these variants in homozygosis are more sensitive to miR-379-induced ABCC2 mRNA down-regulation, leading to lower MRP2 expression ${ }^{[68]}$. Moreover, expression of the c.1249G $>\mathrm{A}$ variant has been associated to enhanced MRP2-mediated sorafenib efflux $^{[59,69]}$.

Owing to its high expression levels, MRP3 (АВCC3) plays a key role in the MDR phenotype of $\mathrm{CCA}^{[48,70]}$ and is also involved in the poor response of HCC to sorafenib ${ }^{[71]}$. The SNP c.-211C>T, which is also present in healthy liver, alters $A B C C 3$ promoter activity although its functional repercussion is controversial ${ }^{[62,63]}$. Regarding MRP4 (ABCC4) and MRP5 (ABCC5), some polymorphisms that modify their stability and substrate specificity have been described ${ }^{[72-74]}$. Nevertheless, their relationship with drug resistance in PLCs remains unknown.

A role of BCRP in HCC chemoresistance has been reported ${ }^{[75]}$, whereas this is not clearly elucidated in the case of $\mathrm{CCA}^{[76]}$. In healthy liver tissue, the expression of c.421C>A (p.Gln141Lys) variant correlates with low BCRP protein levels ${ }^{[77]}$. In addition, several SNPs that modify enhancer activity at the $A B C G 2$ gene locus have been reported ${ }^{[64]}$. Four of these variants (g.89073197A>G, g.88924371A>G, g.89189602G $>A$ and $\mathrm{ABCG} 2 \mathrm{RE}^{*}{ }^{*}$, which is a combination of g.88923906G $>\mathrm{A}$, g.88924176C $>\mathrm{T}$ and g.88924371A $>\mathrm{G}$ ) decreased the promoter activity and hence reduced gene expression, contrary to g.89026428 $\mathrm{A}>\mathrm{C}$ that is associated with increased BCRP activity. Moreover, other genomic variants (g.89073197A $>$ G and g.88924371A>G) increase the ability of ABCG2 gene to bind to nuclear proteins in human hepatoma HepG2 cells ${ }^{[64]}$.

\section{Mutations affecting drug metabolism (MOC-2)}

Changes in drug metabolism, either by reduction in the activation of prodrugs or increased inactivation of active agents, can contribute to chemoresistance. The enzymes involved in MOC-2 participate in either phase I reactions (oxidoreduction of substrates) or in phase II (conjugation with polyatomic groups) processes ${ }^{[39]}$. As many anticancer agents are administered as prodrugs, they require metabolic activation by phase I enzymes. Thus, the presence of variants in genes encoding these enzymes is relevant in cancer therapy, because they may reduce the efficacy of several antitumor drugs and increase their adverse effects ${ }^{[78]}$. In 
Table 3. Germline (G) and somatic (S) mutations affecting coding (c) and non-coding (nc) regions of genes coding phase I enzyme in primary liver cancer

\begin{tabular}{|c|c|c|c|c|c|c|c|c|c|}
\hline Gene & Protein & Genetic mutations & G/S & Region & $\begin{array}{c}\text { Protein } \\
\text { mutations }\end{array}$ & $\begin{array}{c}\text { Functional } \\
\text { consequences }\end{array}$ & $\begin{array}{c}\text { Clinical } \\
\text { consequences }\end{array}$ & Studies & References \\
\hline \multirow[t]{5}{*}{ DPYD } & DPD & c.1700G >T & $\mathrm{S}$ & c & Gly567Val & Moderate & Pathogenic & TCGA-LIHC & TCGA \\
\hline & & c. $589 \mathrm{C}>\mathrm{T}$ & $S$ & c & Pro197Ser & Moderate & Pathogenic & TCGA-LIHC & TCGA \\
\hline & & c. $491 \mathrm{~A}>\mathrm{C}$ & $\mathrm{S}$ & c & Lys164Thr & Moderate & ND & TCGA-LIHC & TCGA \\
\hline & & $c .{ }^{*} 102 A>C$ & S & $\mathrm{nc}$ & 3' UTR & Modifier & ND & TCGA-LIHC & TCGA \\
\hline & & c. $483+820 \mathrm{G}>\mathrm{C}$ & $S$ & $\mathrm{nc}$ & Intron & Modifier & ND & TCGA-LIHC & TCGA \\
\hline DPYS & DHP & c. $650 \mathrm{~A}>\mathrm{T}$ & $\mathrm{S}$ & c & His217Leu & Moderate & ND & TCGA-LIHC & TCGA \\
\hline CYP2D6 & CYP2D6 & c. $100 C>T$ & $\mathrm{~S}$ & c & Pro34Ser & High & $\begin{array}{l}\text { Increased HCC } \\
\text { susceptibility }\end{array}$ & $\begin{array}{l}\text { Cirrhotic / } \\
\text { Fibrotic HCC } \\
\text { patients }\end{array}$ & [79] \\
\hline CYP2C9 & CYP2C9 & c. $1075 A>C$ & $\mathrm{~S}$ & c & Ile359Leu & High & ND & $\begin{array}{l}\text { Cirrhotic / } \\
\text { Fibrotic HCC } \\
\text { patients }\end{array}$ & [79] \\
\hline \multirow[t]{5}{*}{ CYP2A6 } & CYP2A6 & c. $715 C>G$ & S & c & Gln239Glu & Moderate & ND & TCGA-LIHC & TCGA \\
\hline & & c. $323 A>G$ & S & c & Asp108Gly & Moderate & Neutral & TCGA-LIHC & TCGA \\
\hline & & c. ${ }^{\star} 527 C>\mathrm{G}$ & $\mathrm{S}$ & $\mathrm{nc}$ & $3^{\prime}$ UTR & Modifier & ND & TCGA-LIHC & TCGA \\
\hline & & c. ${ }^{\star} 135 A>G$ & S & $\mathrm{nc}$ & $3^{\prime}$ UTR & Modifier & ND & TCGA-LIHC & TCGA \\
\hline & & c. $194+409 A>G$ & S & & Intron & Modifier & ND & TCGA-LIHC & TCGA \\
\hline CYP3A4 & CYP3A4 & c. $-59 A>G$ & S & $\mathrm{nc}$ & $5^{\prime}$ UTR & Modifier & ND & TCGA-LIHC & TCGA \\
\hline \multirow[t]{3}{*}{ CES2 } & CES & c. $278 C>G$ & S & c & Ser93* & High & ND & TCGA-LIHC & TCGA \\
\hline & & c.1524G >A & S & c & Trp508* & High & Neutral & TCGA-LIHC & TCGA \\
\hline & & c.153G $>T$ & S & c & GIn51His & Moderate & ND & TCGA-LIHC & TCGA \\
\hline \multirow[t]{2}{*}{$\mathrm{EH}$} & $\mathrm{EH}$ & c. $337 \mathrm{~T}>\mathrm{C}$ & S & c & Tyr113His & Low & $\begin{array}{l}\text { Increase risk of } \\
\mathrm{HCC}\end{array}$ & HCC patients & {$[81]$} \\
\hline & & c. $416 A>G$ & S & c & His139Arg & High & ND & HCC patients & {$[81]$} \\
\hline NQO1 & NQO1 & c. $127 \mathrm{~T}>\mathrm{G}$ & $\mathrm{S}$ & c & Tyr43Asp & Moderate & ND & TCGA-LIHC & TCGA \\
\hline
\end{tabular}

Data obtained from TCGA database and referred literature. Functional consequences are based on VEP (Variant Effect Predictor; https:// www.ensembl.org/vep) impact: High means that the variant is supposed to cause a high disruptive impact in the protein, which is likely to cause loss of function; Moderate means that the variant may be not disruptive, but results in a decrease effectiveness of the encoded protein; Low means that the variant has low probability to cause a disruptive change in the encoded protein; Modifier is usually referred to non-coding variants, whose impact is difficult to determine, although they can be involved in transcription or splicing changes. HCC: hepatocellular carcinoma; ND: not described; TCGA: the cancer genome atlas; TCGA-LIHC: the cancer genome atlas - liver hepatocellular carcinoma

addition, inactivation by phase II enzymes of anticancer drugs, such as TKIs, is an important systemic and intratumor mechanism involved in determining the response to pharmacological treatment ${ }^{[80]}$. Available information regarding the presence of germline and somatic mutations in PLC affecting genes encoding phase I and II enzymes is summarized in Tables 3 and 4, respectively.

Phase I Enzymes

Somatic pharmacogenetics: Cytochrome P450 (CYP) includes a large group of enzymes located in mitochondrial membranes or in the endoplasmic reticulum that play a crucial role in metabolism ${ }^{[82]}$. In humans, the most important CYPs regarding drug metabolism are CYP1A2, CYP2A6, CYP2 B6, CYP2C6, CYP2D6, CYP2E6, CYP2C8, CYP2C9 and $\mathrm{CYP}_{3} \mathrm{~A} 4 / 5$, which are responsible for $90 \%$ of the metabolic inactivation of drugs currently used ${ }^{[83]}$. CYPs are abundantly expressed in HCC, which is consistent with the fact that drugs are more rapidly metabolized in the tumor than in the surrounding liver tissue ${ }^{[84]}$. Therefore, changes in CYP activity can contribute to HCC chemoresistance ${ }^{[8]}$. For instance, CYP2A6 activates the prodrug tegafur/uracil to 5-FU. An investigation on polymorphisms affecting CYP2A6 in Japanese patients with $\mathrm{HCC}$ has reported a frequency of 0.233 for the CYP2 $6^{*} 4$ genetic variant, which results in CYP2A6 gene deletion, in heterozygosis, whereas the homozygous genotype was found in 5 out of $58 \mathrm{HCC}$ patients ${ }^{[86]}$. Other study has described that the allelic frequency of the mutant homozygote CYP2D6 c.100C>T (p.Pro34Ser) variant is significantly reduced in HCC patients ${ }^{[79]}$. The authors reported an increased intrinsic clearance of drugs, such as linifanib (ABT-869) and banoxantrone (AQ4N), when the CYP2C9 variant c.1075A>C 
Table 4. Germline (G) and somatic (S) mutations affecting coding (c) and non-coding (nc) regions in genes coding phase II enzymes in primary liver cancer

\begin{tabular}{|c|c|c|c|c|c|c|c|c|c|}
\hline Gene & Protein & Genetic mutations & $\mathbf{G} / \mathbf{S}$ & Region & $\begin{array}{c}\text { Protein } \\
\text { mutations }\end{array}$ & $\begin{array}{c}\text { Functional } \\
\text { consequences }\end{array}$ & $\begin{array}{c}\text { Clinical } \\
\text { consecuences }\end{array}$ & Studies & References \\
\hline \multirow[t]{2}{*}{ DCK } & DCK & c. ${ }^{\star} 823 C>T$ & S & $\mathrm{nc}$ & 3' UTR & Modifier & ND & TCGA-LIHC & TCGA \\
\hline & & c. ${ }^{\star} 157 \mathrm{G}>\mathrm{T}$ & S & $\mathrm{nc}$ & 3' UTR & Modifier & ND & TCGA-LIHC & TCGA \\
\hline \multirow[t]{4}{*}{ CDA } & CDA & c. $208 \mathrm{G}>\mathrm{A}$ & G & c & Ala70Thr & High & $\begin{array}{l}\text { Neutropenia } \\
\text { and decreased } \\
\text { clearance of } \\
\text { gemcitabine }\end{array}$ & $\begin{array}{l}\text { Several types } \\
\text { of cancer }\end{array}$ & {$[87]$} \\
\hline & & c. $271 \mathrm{~A}>\mathrm{G}$ & S & c & Met91Val & Moderate & Neutral & TCGA-LIHC & TCGA \\
\hline & & c. $267-1 \mathrm{G}>\mathrm{A}$ & S & c & Splice acceptor & High & Pathogenic & TCGA-LIHC & TCGA \\
\hline & & c.157T>C & S & c & Cys53Arg & Moderate & ND & TCGA-LIHC & TCGA \\
\hline \multirow[t]{2}{*}{ MET } & MET & c. $65 \mathrm{G}>\mathrm{T}$ & S & c & Ser22Ile & Moderate & ND & TCGA-LIHC & TCGA \\
\hline & & $\begin{array}{l}\text { c. } 3713 A>T \\
\text { c. } 3767 A>T\end{array}$ & S & c & $\begin{array}{l}\text { His1238Leu } \\
\text { His1256Leu }\end{array}$ & $\begin{array}{l}\text { Moderate } \\
\text { Moderate }\end{array}$ & $\begin{array}{l}\text { ND } \\
\text { ND }\end{array}$ & $\begin{array}{l}\text { TCGA-LIHC } \\
\text { TCGA-LIHC }\end{array}$ & $\begin{array}{l}\text { TCGA } \\
\text { TCGA }\end{array}$ \\
\hline \multirow[t]{2}{*}{ SULT1A1 } & SULT1A1 & $\begin{array}{l}\text { c.-265_- } \\
\text { 258delGTGAGGGG }\end{array}$ & $S$ & $\mathrm{nc}$ & $5^{\prime}$ UTR & Modifier & ND & TCGA-CHOL & TCGA \\
\hline & & $\begin{array}{l}\text { c.-4-460_-4- } \\
\text { 453delGTGAGGGG }\end{array}$ & S & $\mathrm{nc}$ & Intron & Modifier & ND & TCGA-CHOL & TCGA \\
\hline \multirow[t]{4}{*}{ UGT2B7 } & UGT2B7 & c. $311 C>A$ & $S$ & c & Thr104Lys & Moderate & Neutral & TCGA-LIHC & TCGA \\
\hline & & c. $22 \mathrm{G}>\mathrm{T}$ & S & c & Val8Leu & Moderate & ND & TCGA-LIHC & TCGA \\
\hline & & c.282_283delTA & S & c & Lys95Glufs`26 & High & ND & TCGA-LIHC & TCGA \\
\hline & & c.589_591delGTT & S & c & Val197del & Moderate & ND & TCGA-LIHC & TCGA \\
\hline UGT1A1 & UGT1A1 & c.725T>A & S & c & Val242Glu & Moderate & ND & TCGA-LIHC & TCGA \\
\hline \multirow[t]{4}{*}{ UGT1A3 } & UGT1A3 & c. $779 A>G$ & S & c & Asp260Gly & Moderate & ND & TCGA-LIHC & TCGA \\
\hline & & $c .457 C>T$ & S & c & Pro153Ser & Modifier & ND & TCGA-LIHC & TCGA \\
\hline & & c. $867+13031 C>T$ & S & c & Intron & Modifier & ND & TCGA-LIHC & TCGA \\
\hline & & c. $867+17971 A>G$ & S & c & Intron & Moderate & ND & TCGA-LIHC & TCGA \\
\hline UGT1A9 & UGT1A9 & c. $668 \mathrm{~T}>\mathrm{A}$ & $\mathrm{s}$ & c & Phe223Tyr & Moderate & Neutral & TCGA-LIHC & TCGA \\
\hline
\end{tabular}

Data obtained from TCGA database (https://cancergenome.nih.gov/) and referred literature. Functional consequences are based on VEP (Variant Effect Predictor; https://www.ensembl.org/vep) impact: High means that the variant is supposed to cause a high disruptive impact in the protein, which is likely to cause loss of function; Moderate means that the variant may be not disruptive, but results in a decrease effectiveness of the encoded protein; Modifier is usually referred to non-coding variants, whose impact is difficult to determine, although they can be involved in transcription or splicing changes. ND: not described; TCGA: the cancer genome atlas; TCGA-LIHC: the cancer genome atlas - liver hepatocellular carcinoma; TCGA-CHOL: the cancer genome atlas - cholangiocarcinoma

(p.Ile359Leu) was expressed in $\mathrm{HCC}^{[79]}$. CYP3A4 is the major enzyme involved in metabolism of drugs, which includes sorafenib, gefitinib and paclitaxel. However, CYP3A4 is usually very poorly expressed in tumors and cell lines of different origin ${ }^{[88]}$. Thus, CYP3A4 activity has been found markedly decreased in tumors of 96 patients with HBV-positive HCC, as compared with the adjacent non-tumor tissue ${ }^{[85]}$.

Epoxide hydrolase (EH) metabolizes epoxy eicosatrienoinc acids (EETs) and other lipid epoxides and is involved in a variety of biological activities, such angiogenesis and cancer metastasis ${ }^{[89]}$. The microsomal form of $\mathrm{EH}(\mathrm{mEH})$ has been characterized and two SNPs in the coding region, c.337T>C (p.Tyr113His) and c.416A $>\mathrm{G}$ (p.His139Arg) have been identified. Both variants have lower enzyme activity compared to the wild-type protein ${ }^{[0,91]}$. The relationship between these variants and HCC is poorly understood ${ }^{[92]}$. In a metaanalysis involving 1,696 HCC cases, the His113-mEH allele was significantly associated with increased risk of HCC, whereas the Arg139-mEH genotype had no association with HCC development ${ }^{[80]}$.

Dihydropyrimidine dehydrogenase (DPD, gene symbol DPYD), which is highly expressed in human liver, is involved in the first step of pyrimidines breakdown. DPD converts thymine to 5,6-dihydrothymine and uracil to 5,6-dihydrouracil. Accordingly, this catalytic activity can modify the effectiveness of 5-FU ${ }^{[93]}$. Thus, intratumor levels of this drug can vary among patients, despite of receiving the same dose $\mathrm{e}^{[94]}$. DPD polymorphisms play a key role in this differential response ${ }^{[86]}$. Although more than 200 polymorphisms have been identified, in vitro studies have shown that only few of them have a deleterious impact on DPD 
enzymatic activity ${ }^{[95]}$. Mutations related to this gene are described in Table 3. A second enzyme involved in 5-FU catabolism is dihydropyrimidinase (DHP gene symbol DPYS), which catalyzes the conversion of dihydro-5,6-fluorouracil to fluoro- $\beta$-ureidopropionate. DHP deficiency caused by heterozygous missense and nonsense polymorphisms in DPYS gene may increase 5-FU toxicity ${ }^{[96]}$.

$\mathrm{NAD}(\mathrm{P}) \mathrm{H}$ quinone oxidoreductase 1 (NQO1) catalyzes the reduction of quinones and nitro derivatives using NADP or NADPH as cofactors. NQO1 expression leads to a favorable position for the development of tumor cells by protecting them from oxidative stress and chemotherapeutic agents, resulting in cancer progression and chemoresistance, as has been described for $\mathrm{HCC}^{[97]}$. In CCA, NQO1 plays a role in modulating sensitivity of cancer cells to gemcitabine when given in combination with dicoumarol, which enhances gemcitabine cytotoxicity in CCA cells with high NQO1 activity ${ }^{[s]}$. The most prominent and frequent variant of NQO1 is c.609C $>\mathrm{T}$ (p.Pro187Ser), which has been associated to an increased risk of colorectal cancer and colorectal adenoma $^{[99]}$ and poor OS in non-small-cell lung cancer ${ }^{[100]}$.

\section{Phase II Enzymes}

Germline pharmacogenetics: Cytidine deaminase (CDA) is the major enzyme of gemcitabine inactivation. This enzyme catalyzes the irreversible hydrolytic deamination of cytidine and deoxycytidine to uridine and deoxyuridine, respectively. CDA, which is poorly expressed in liver tissue ${ }^{[101]}$, presents several SNPs that have been associated with higher expression and enzymatic activity of CDA and poorer disease outcome in patients treated with gemcitabine. Among the most studied variants are two non-synonymous SNPs, c.79A $>C$ (p.Lys27Gln) and c.208G $>A$ (p.Ala70Thr), and three SNPs in the CDA promoter region that possibly affect $\mathrm{CDA}$ expression, c. $-451 \mathrm{G}>\mathrm{A}$, c.- $-92 \mathrm{~A}>\mathrm{G}$ and c.-31delC. Another well-studied variant is the synonymous SNP c.435C $>$ T (p.Thr145=), located at exon $4^{[102]}$.

Somatic pharmacogenetics: The somatic mutation c.208G>A (p.Ala70Thr) decreases the activity of CDA in pancreas, lung and mesothelium cancer, which has clinical impact in patients treated with gemcitabine, cisplatin and 5-FU ${ }^{[87,91]}$. Moreover, c.208G $>\mathrm{A}$ has been associated with a reduced clearance of gemcitabine and increased neutropenia when patients were co-treated with gemcitabine and 5-FU or platinum-containing drugs ${ }^{[87]}$. The impact of c.79A $>\mathrm{C}$ and c.435C $>\mathrm{T}$ in the clinical outcome of 126 advanced non-small-cell lung cancer patients treated with gemcitabine-platinum-regimens has been evaluated ${ }^{[103]}$. The results indicated that patients with the AC genotype had significantly longer time to progression and OS than patients with CC genotype.

Deoxycytidine kinase (DCK) catalyzes the first rate-limiting phosphorylation step in the activation of deoxycytidine analogs. The combination of three mutations, c.511G>A (p.Glu171Lys), c.739G>A, (p.Glu247Lys) and c.745G>A (p.Leu249Met) in DCK sensitizes a panel of cancer cell lines to treatment with gemcitabine ${ }^{[104]}$.

Several SNPs have been suggested to affect glutathione S-transferases function and favor carcinogenesis. The SNP c.-67C $>$ T in the GSTA1 promoter, when expressed in hepatocytes, reduces GSTA1 expression. Moreover, the TT genotype is more frequent in HCC than in healthy controls. In addition, GSTA1 expression is lower in HCC than in healthy livers ${ }^{[105]}$.

Sulfotransferases (SULT) catalyze the addition of a sulfonate moiety. Three human SULT families have been identified: SULT1, SULT2 and SULT4 ${ }^{[106]}$. SULT1A1 metabolizes brivanib, a drug used in phase III trials as the first-line treatment of $\mathrm{HCC}^{[107]}$. SULT1A1 is up-regulated in patients with HCC secondary to chronic HBV infection ${ }^{[108]}$. Table 4 shows the mutations in SULT1A1 observed in PLC. In order to elucidate the role of these mutations in the chemoresistance of these tumors, further investigations are required.

Uridine 5'-diphospho glucuronosyl transferases (UGT) are a group of phase II drug-metabolizing enzymes that catalyze the glucuronidation of xenobiotics and endogenous compounds ${ }^{[39]}$. A reduction in the activity of 
UGT1As and UGT2B7 has been observed in HBV-positive HCC ${ }^{[109]}$. In addition, down-regulation of UGT1A9 has been related to lower sorafenib metabolism in microsomes of HCC cells ${ }^{[110]}$. UGT2B7 is a p53 target gene in liver cells that could promote intratumor or systemic metabolism and clearance of cytotoxic agents and other drugs administered together. Thus, UGT2B7 may be related to reduced efficacy of cancer therapy ${ }^{[111]}$. A novel class of human UGT isoforms, namely i2s, has been described. In comparison to isoforms 1 (i1s), i2s isoforms utilize the shorter exon $5 b$ instead of incorporating the usual C-terminus exon $5 \mathrm{a}$, which causes a premature arrest of translation and subsequent loss of the transmembrane domain. Therefore, UGT i2s isoforms are located at the lumen and cytoplasm rather than at the membrane of the endoplasmic reticulum, which results in the lack of glucuronidation activity but acting in a dominant-negative manner. Increased i2 isoforms expression in PLCs has been found ${ }^{[112]}$. Somatic mutations affecting UGTs described in TCGA database are listed in Table 4.

\section{MOLECULAR TARGETS AND SURVIVAL PATHWAYS}

Three major types of molecular alterations have been reported to be at the origin of hepatocarcinogenesis: i) Aberrant cell proliferation and survival due to a constitutive activation of signaling pathways, such as EGFRRas-MAPK, PI3K-AKT-mTOR, HGF/MET, Wnt- $\beta$-catenin and others; ii) Deregulation of proapoptotic machinery elements, such as 53 and Bcl2; and iii) Stimulation of neo-angiogenesis, which is crucial for tumor development ${ }^{[2]}$. Mutations in genes involved in these pathways are expected to determine the response to drugs acting on these targets.

\section{Molecular targets of chemotherapeutic agents (MOC-3)}

Mutations or changes in the expression levels of target genes could prevent efficient drug-target interaction leading to treatment failure ${ }^{[113]}$. Although TKIs are useful in the treatment of many tumors, their efficacy is often hampered by changes in their targets. For instance, the multikinase inhibitor sorafenib reduces tumor cell proliferation and angiogenesis in HCC, which is due in part to its interaction with receptors for several growth factors, such as EGF (EGFR), VEGF (VEGFR) and PDGF (PDGFR) ${ }^{[6]}$.

\section{Germline pharmacogenetics}

Although somatic mutations are the most frequent changes among the targets of antitumor drugs, some target genes belonging to the VEGF family are also affected by germline mutations. This is the case of KDR gene (also known as VEGFR or VEGFR2), in which the germline SNP c.1416A>T (p.Gln472His), has been described in an East Asian HCC cohort. In this case, patients with two wild-type alleles and heterozygous (AT) genotype have decreased progression-free survival (PFS) and OS compared with homozygous patients for the mutant allele (TT $)^{[114]}$. This polymorphism has also been associated with toxicity and adverse reactions to sorafenib, including increasing risk of hypertension and hand-foot skin reactions in TT patients ${ }^{[115]}$. Moreover, this mutation has been linked to the response to capecitabine/oxaliplatin and cyclophosphamide in colorectal ${ }^{[116]}$ and prostatic ${ }^{[117]}$ tumors, respectively. In addition, the germline polymorphism c.-94C>G at the 5'UTR region of the VEGFA gene has been associated with the outcome of prostatic and colorectal cancer patient ${ }^{[116]}$. In HCC, homozygous genotype for the G allele has been related to lower PFS and OS than homozygous patients for $\mathrm{C}$ allele and heterozygous genotypes ${ }^{[118]}$.

\section{Somatic pharmacogenetics}

Acquired resistance to TKI treatment can be due to somatic mutations in a wide variety of target genes. Exome sequencing analysis of 243 HCCs revealed 161 mutated genes which could be classified into 11 recurrent pathways. The most frequently altered pathways were PI3K-AKT-mTOR (51\%) and MAPK (43\%). Although target genes of TKIs (EGFR, VEGFR1, KDR, VEGFC, VEGFA and BRAF) were affected by less than $1 \%$ of all mutations, these alterations were predicted to have functional consequences ${ }^{[119]}$. Table 5 summarizes mutations described in HCC and CCA. Some of these mutations, for instance affecting EGFR, VEGFR1 and VEGFC, are predicted to alter the function of these proteins ${ }^{[119]}$. An EGFR polymorphism, c.2369C $>\mathrm{T}$ 
Table 5. Germline (G) and somatic (S) mutations affecting coding (c) and non-coding (nc) regions in target genes of anticancer drugs in primary liver cancer

\begin{tabular}{|c|c|c|c|c|c|c|c|c|c|}
\hline Gene & Protein & Genetic mutation & G/S & Region & $\begin{array}{c}\text { Protein } \\
\text { mutation }\end{array}$ & $\begin{array}{c}\text { Functional } \\
\text { consequences }\end{array}$ & $\begin{array}{c}\text { Clinical } \\
\text { consequences }\end{array}$ & Studies & Ref. \\
\hline \multirow[t]{3}{*}{ BRAF } & BRAF & c.1799A >T & $\mathrm{S}$ & c & Val600Glu & Moderate & Decreased OS & CCA patients & [120] \\
\hline & & & & & & & ND & Biliary Adenoma & [121] \\
\hline & & c.1910T>A & S & c & Val637Glu & $\begin{array}{l}\text { Activation of } \\
\text { MAPK and } \\
\text { AKT pathways }\end{array}$ & $\begin{array}{l}\text { Enhanced } \\
\text { proliferation }\end{array}$ & $\mathrm{HCC}$ in vivo & {$[122,123]$} \\
\hline \multirow[t]{11}{*}{ EGFR } & EGFR & c. $2464 G>A$ & S & c & Ala822Pro & Moderate & ND & HCC patients & [119] \\
\hline & & $c .67 C>T$ & S & c & Arg23Trp & ND & Benign & HCC patients & [119] \\
\hline & & c. $374 A>G$ & S & c & Tyr125Cys & ND & ND & HCC patients & $\mathrm{dbEMT}$ \\
\hline & & $\begin{array}{l}\text { c. } 2165 \text { 2173 } \\
\text { dupCCAGCGTGG }\end{array}$ & S & c & $\begin{array}{l}\text { Ala722_ } \\
\text { Val724dup }\end{array}$ & Moderate & ND & TCGA-LIHC & TCGA \\
\hline & & c. $2095 A>G$ & S & c & Ile699Val & Moderate & Pathogenic & TCGA-LIHC & TCGA \\
\hline & & c. $3313 \mathrm{~A}>\mathrm{T}$ & S & c & Thr1105Ser & Moderate & Neutral & TCGA-LIHC & TCGA \\
\hline & & c.1097C>G & S & c & Pro366Arg & Moderate & Pathogenic & TCGA-LIHC & TCGA \\
\hline & & $\begin{array}{l}\text { c.926_945 } \\
\text { delCGAATATTA } \\
\text { AACACTTCAAA }\end{array}$ & S & c & Thr309fs*17 & High & ND & TCGA-LIHC & TCGA \\
\hline & & c. $3349 \mathrm{~A}>\mathrm{T}$ & S & $c$ & Ser1117Cys & Moderate & ND & TCGA-LIHC & TCGA \\
\hline & & c.1881-2577C>T & S & $\mathrm{nc}$ & Intron & Modifier & ND & TCGA-LIHC & TCGA \\
\hline & & c. $1072+33 \mathrm{G}>\mathrm{T}$ & S & $\mathrm{nc}$ & Intron & Modifier & No significant & TCGA-LIHC & TCGA \\
\hline \multirow[t]{10}{*}{ FLT1 } & VEGFR1 & c. $2306 \mathrm{G}>\mathrm{A}$ & S & c & Ala769Val & Moderate & ND & HCC patients & [119] \\
\hline & & c.2196_2198delTGA & S & c & Ser733* & High & ND & HCC patients & [119] \\
\hline & & c. $2110 C>T$ & S & c & Glu704Lys & Moderate & ND & HCC patients & [119] \\
\hline & & c. $1796 C>G$ & S & c & Thr599Arg & Moderate & Pathogenic & TCGA-LIHC & TCGA \\
\hline & & c.2021delG & S & c & Ser674fs*12 & Modifier & ND & TCGA-LIHC & TCGA \\
\hline & & c.166dupG & S & c & Glu56fs $\star 5$ & High & ND & TCGA-CHOL & TCGA \\
\hline & & c. $1988 A>C$ & S & c & Lys663Thr & Modifier & ND & TCGA-LIHC & TCGA \\
\hline & & c. $679 A>T$ & S & c & Asn227Tyr & Moderate & Pathogenic & TCGA-LIHC & TCGA \\
\hline & & c.1997A>T & S & c & Asn666lle & Moderate & ND & TCGA-LIHC & TCGA \\
\hline & & c. $3636-1 G>C$ & S & $\mathrm{nc}$ & Splice acceptor & High & Pathogenic & TCGA-LIHC & TCGA \\
\hline \multirow[t]{12}{*}{ KDR } & VEGFR2 & c.1416A>T & G & c & $\mathrm{Gln} 472 \mathrm{His}$ & ND & $\begin{array}{l}\text { Increased PFS } \\
\text { and OS }\end{array}$ & HCC patients & {$[114]$} \\
\hline & & c. $713 A>G$ & S & c & Val238Ala & ND & Benign & HCC patients & [119] \\
\hline & & c. $2935 G>A$ & S & c & Glu979Lys & Moderate & ND & TCGA-CHOL & TCGA \\
\hline & & c.1054G>T & $S$ & c & Ala352Ser & Moderate & Pathogenic & TCGA-LIHC & TCGA \\
\hline & & c. $1772 T>G$ & S & c & Leu591Arg & Moderate & Neutral & TCGA-LIHC & TCGA \\
\hline & & c. $3944 A>G$ & S & c & Asp1315Gly & Moderate & Pathogenic & TCGA-LIHC & TCGA \\
\hline & & c.1297G > T & S & c & Asp433Tyr & Moderate & ND & TCGA-LIHC & TCGA \\
\hline & & c. $3957 C>A$ & S & c & Tyr1319* & High & Pathogenic & TCGA-LIHC & TCGA \\
\hline & & c. $3152 \mathrm{G}>\mathrm{A}$ & S & c & Arg1051GIn & Moderate & Pathogenic & TCGA-CHOL & TCGA \\
\hline & & c. $1368 C>G$ & S & c & Ile456Met & Moderate & Pathogenic & TCGA-LIHC & TCGA \\
\hline & & c. $2398 \mathrm{G}>\mathrm{C}$ & S & c & Gly800Arg & Moderate & Pathogenic & TCGA-LIHC & TCGA \\
\hline & & c. ${ }^{\star} 172 \mathrm{G}>\mathrm{A}$ & $\mathrm{S}$ & $\mathrm{nc}$ & $3^{\prime} \mathrm{UTR}$ & Modifier & ND & TCGA-LIHC & TCGA \\
\hline \multirow[t]{4}{*}{ VEGFA } & VEGFA & c. $-94 C>G$ & G & $\mathrm{nc}$ & $5^{\prime} \cup T R$ & ND & $\begin{array}{l}\text { Decreased } \\
\text { PFS and OS }\end{array}$ & HCC patients & [118] \\
\hline & & $\begin{array}{l}\text { c.332_346del } \\
\text { GCCCGGGCC } \\
\text { TCGGGC }\end{array}$ & S & c & $\begin{array}{l}\text { Ala112__ } \\
\text { Gly116del }\end{array}$ & Moderate & ND & TCGA-LIHC & TCGA \\
\hline & & c. ${ }^{\star} 285 \mathrm{~A}>\mathrm{G}$ & S & $\mathrm{nc}$ & $3^{\prime} U T R$ & Modifier & ND & TCGA-CHOL & TCGA \\
\hline & & c. $308+1 G>C$ & S & $\mathrm{nc}$ & Splice donor & High & ND & TCGA-LIHC & TCGA \\
\hline \multirow[t]{9}{*}{ VEGFC } & VEGFC & c. $986 C>T$ & $S$ & c & Gly329Glu & Moderate & ND & HCC patients & [119] \\
\hline & & c. $367 C>A$ & S & c & Asp123Tyr & Moderate & ND & HCC patients & [119] \\
\hline & & c. $235 \mathrm{~T}>\mathrm{C}$ & S & c & Lys79Glu & Moderate & ND & HCC patients & [119] \\
\hline & & c. $842 \mathrm{G}>\mathrm{A}$ & S & c & Gly281Glu & Moderate & ND & TCGA-LIHC & TCGA \\
\hline & & c. $938 \mathrm{~A}>\mathrm{G}$ & S & c & Asn313Ser & Moderate & ND & TCGA-LIHC & TCGA \\
\hline & & c. $341 \mathrm{~A}>\mathrm{T}$ & S & c & Tyr114Phe & Moderate & ND & TCGA-LIHC & TCGA \\
\hline & & c. $1037 C>G$ & S & c & Thr346Ser & Moderate & ND & TCGA-LIHC & TCGA \\
\hline & & c.1253T>G & S & c & Met418Arg & Moderate & ND & TCGA-LIHC & TCGA \\
\hline & & $c .820 G>C$ & S & c & Asp274His & Moderate & ND & TCGA-CHOL & TCGA \\
\hline
\end{tabular}




\begin{tabular}{|c|c|c|c|c|c|c|c|}
\hline c. $-17 C>A$ & $\mathrm{~s}$ & $\mathrm{nc}$ & $5^{\prime}$ UTR & Modifier & ND & TCGA-LIHC & TCGA \\
\hline g.177608775T>C & $\mathrm{S}$ & $\mathrm{nc}$ & Intron & ND & $\begin{array}{l}\text { Decreased } \\
\text { PFS and OS }\end{array}$ & HCC patients & {$[118]$} \\
\hline
\end{tabular}

Data obtained from referred literature, dbEMT, and TCGA database. Functional consequences are based on VEP (Variant Effect Predictor; https://www.ensembl.org/vep) impact: High means that the variant is supposed to cause a high disruptive impact in the protein, which is likely to cause loss of function; Moderate means that the variant may be not disruptive, but results in a decrease effectiveness of the encoded protein; Modifier is usually referred to non-coding variants, whose impact is difficult to determine, although they can be involved in transcription or splicing changes. OS: overall survival; PFS: progression-free survival; CCA: cholangiocarcinoma; HCC: hepatocellular carcinoma; IHCA: Inflammatory hepatocellular adenomas; ND: not described; TCGA: the cancer genome atlas; TCGA-LIHC: the cancer genome atlas - liver hepatocellular carcinoma; TCGA-CHOL: the cancer genome atlas - cholangiocarcinoma

(p.Thr790Met), has been described in non-small-cell lung cancer, and prevents gefitinib- and erlotinibinduced TKR inhibition ${ }^{[124,125]}$. Somatic mutations in ESR1, TYMS and EGFR genes related to drug resistance have also been reported in $\mathrm{PLC}^{[91]}$. A variant in an intron of VEGFC (g.177608775T>C) has been associated with sorafenib efficacy in HCC patients. CC genotype of this mutation is accompanied by a decrease in PFS and OS as compared with patients bearing CT or TT genotype ${ }^{[116]}$. In iCCA, EGFR amplification has been associated with the response to gefitinib (anti-EGFR therapy) ${ }^{[126]}$.

Concerning BRAF, which is another major target of sorafenib, the missense mutation c.1799T>A (p.Val600Glu) must be highlighted. This mutation has been found in many malignant tumors, such as melanoma, thyroid cancer $^{[123]}$, colorectal cancer ${ }^{[127]}$, but also $\mathrm{HCC}^{[119]}$ and iCCA ${ }^{[120]}$. In patients with iCCA, OS was lower in those with mutated BRAF (7.4\% of cases) than in wild-type cases. The murine ortholog of this mutation in mouse (c.1910T>A; p.Val637Glu), is a frequent feature in mouse liver cancer. In diethylnitrosamine-induced mouse hepatocarcinogenesis, c.1910T>A mutation correlated with Erk1/Akt hyperphosphorylation, suggesting an activation of MAPK and AKT pathways that results in stimulated cell proliferation ${ }^{[120,123]}$. Nevertheless, a relationship between these mutations and the response to TKIs has not been well characterized.

\section{DNA repair mechanisms (MOC-4)}

Cancer cells can repair genome perturbations that are induced by antitumor-drugs through diverse mechanisms that depend on the type of damage suffered by DNA ${ }^{[113]}$. DNA repairing machinery includes direct reversal of lesions by enzymes, such as O-6-methylguanine-DNA methyltransferase (MGMT), nucleotide and base excision repair (NER and BER, respectively), DNA mismatch repair (MMR), homologous recombination (HR) and non-homologous end joining (NHEJ). Deregulated expression and the appearance of mutations in genes of the repair machinery have been observed in a variety of tumors. Since many cytotoxic drugs used in the treatment of PLC act through alterations in DNA structure of cancer cells, MOC-4 play an important role in the response of these tumors to chemotherapy. Table 6 provides a summary of both germline and somatic mutations affecting DNA repair genes in HCC and CCA.

\section{Germline pharmacogenetics}

NER is the most important pathway involved in the elimination of bulky adducts induced by UV irradiation and alkylating agents, such as platinum derivatives. More than 25 polypeptides participate in NER ${ }^{[128]}$. Germline variants in NER elements have been found in several cancers and some studies have related these alterations to the lack of response to platinum-based chemotherapy ${ }^{[129,130]}$. However, mutations in these genes are rarely found in HCC.

BER pathway also plays an essential role in DNA damage repair induced by alkylating agents and irradiation. APE1 is an endonuclease involved in this process that recognizes and cleaves abasic (apurinic/apyrimidinic) sites, where XRCC1 forms a complex with a DNA ligase to repair the gaps that have resulted from base excision. In HCC patients, two genetic polymorphisms in XRCC1 (c.580C>T; p.Arg194Trp) and APE1 (c.444T>G; p.Asp148Glu) have been associated with resistance to cisplatin ${ }^{[131]}$. 
Table 6. Germline (G) and somatic (S) mutations affecting coding (c) and non-coding (nc) regions of repair genes in primary liver cancer

\begin{tabular}{|c|c|c|c|c|c|c|c|c|c|}
\hline Gene & Protein & $\begin{array}{c}\text { Genetic } \\
\text { mutation }\end{array}$ & G/S & Region & $\begin{array}{c}\text { Protein } \\
\text { mutation }\end{array}$ & $\begin{array}{c}\text { Functional } \\
\text { consequences }\end{array}$ & Clinical consequences & Studies & References \\
\hline APEX1 & APE1 & c. $444 T>G$ & $G$ & c & Asp148Glu & ND & Cisplatin resistance & HCC patients & [131] \\
\hline \multirow[t]{6}{*}{ BRCA1 } & BRCA1 & c.185delT & G & c & & High & Better OS. Therapy response & CCA patients & [132] \\
\hline & & c. $5503 C>T$ & S & c & $\operatorname{Arg} 1835^{\star}$ & Moderate & Better OS. Therapy response & CCA patients & [132] \\
\hline & & c.1961delA & S & c & Lys $654 \mathrm{fs}^{\star} 47$ & ND & Better OS. Therapy response & CCA patients & [132] \\
\hline & & c. $5153 \mathrm{G}>\mathrm{T}$ & S & c & Trp1718Leu & Moderate & Better OS. Therapy response & CCA patients & [132] \\
\hline & & c. $2293 G>A$ & S & c & Glu765Lys & ND & Better OS. Therapy response & CCA patients & [132] \\
\hline & & & S & c & Asp $825 f s^{\star} 21$ & ND & Better OS. Therapy response & CCA patients & [132] \\
\hline \multirow[t]{7}{*}{ BRCA2 } & BRCA2 & c. 6503delT & G & c & & High & Better OS. Therapy response & CCA patients & [132] \\
\hline & & c. 6174delT & G & c & & High & Better OS. Therapy response & CCA patients & [132] \\
\hline & & c.9976A>T & $S$ & c & Lys3326* & Moderate & Better OS. Therapy response & CCA patients & [132] \\
\hline & & & S & c & Leu $2368 \mathrm{fs}{ }^{\star} 8$ & ND & Better OS. Therapy response & CCA patients & [132] \\
\hline & & & S & c & Asn991fs ${ }^{\star} 3$ & ND & Better OS. Therapy response & CCA patients & [132] \\
\hline & & c. $9154 \mathrm{C}>\mathrm{T}$ & S & c & Arg3052Trp & Moderate & Better OS. Therapy response & CCA patients & [132] \\
\hline & & c. $9257 G>C$ & S & c & Gly3086Ala & ND & Better OS. Therapy response & CCA patients & [132] \\
\hline \multirow[t]{2}{*}{ ERCC1 } & ERCC1 & c. $133 A>G$ & S & c & Ser45Gly & ND & ND & HCC patients & cBioportal \\
\hline & & $c .43 G>T$ & S & c & Gly15Trp & ND & ND & HCC patients & cBioportal \\
\hline \multirow{4}{*}{$\begin{array}{l}\text { ERCC2/ } \\
\text { XPD }\end{array}$} & ERCC2/ & $c .1450 A>G$ & S & c & Thr484Ala & ND & ND & HCC patients & cBioportal \\
\hline & XPD & c. $215 \mathrm{~A}>\mathrm{T}$ & S & c & Tyr72Phe & ND & ND & HCC patients & cBioportal \\
\hline & & c.1853T>G & S & c & Val618Gly & ND & ND & HCC patients & cBioportal \\
\hline & & c. $1378 A>G$ & S & c & Thr460Ala & ND & ND & HCC patients & cBioportal \\
\hline NHEJ1 & NHEJ1/XLF & c. $518 C>T$ & S & c & Thr173Met & ND & ND & HCC patients & cBioportal \\
\hline XRCC1 & $\mathrm{XRCC1}$ & c. $580 \mathrm{C}>\mathrm{T}$ & G & c & Arg194Trp & ND & Cisplatin resistance & HCC patients & {$[131]$} \\
\hline
\end{tabular}

Data obtained from cBioportal and referred literature. Functional consequences are based on VEP (Variant Effect Predictor; https:// www.ensembl.org/vep) impact: High means that the variant is supposed to cause a high disruptive impact in the protein, which is likely to cause loss of function; Moderate means that the variant may be not disruptive, but results in a decrease effectiveness of the encoded protein; Modifier is usually referred to non-coding variants, whose impact is difficult to determine, although they can be involved in transcription or splicing changes. CCA: cholangiocarcinoma; HCC: hepatocellular carcinoma; OS: overall survival; ND: not determined

Germline mutations in several genes belonging to DNA repair pathways are more common in CCA. Variants in BRCA and RAD51 genes (HR pathway) and in MHL1 and MSH2 genes (MRR repair pathway) have been found in $11 \%$ of CCA analyzed ${ }^{[133]}$, although a relationship between these mutations and treatment response or OS has been rarely reported. In a multicenter retrospective study of CCA patients, improved OS in patients harboring pathogenic BRCA1/2 mutations treated with platinum-based therapy and/or PARP inhibitors (PARPi) have been described ${ }^{[132]}$. This suggests that CCA patients could benefit from targeted therapy, such as PARPi administration, as occurs in other BRCA-associated tumors ${ }^{[134]}$.

\section{Somatic pharmacogenetics}

Somatic mutations in NER genes are rarely found in HCC. ERCC1, one of the key components in this repair mechanism, is mutated at low frequency $(<1 \%)$. In a cohort of 372 HCC samples collected by TCGA only two ERCC1 mutations (c.133A>G; p.Ser45Gly and c.43G>T; p.Gly15Trp) were found in two tumors, even though the functional consequences are unknown. However, this gene is frequently overexpressed in HCC tumors, being associated with cisplatin resistance ${ }^{[135]}$. Another essential NER protein, responsible for DNA damage recognition, is XPC, which is also overexpressed in HCC and could be related to chemoresistance ${ }^{[136]}$. Nevertheless, XPC mutations with clinical relevance have not been reported in HCC. The XPD (or ERCC2) gene encodes a DNA helicase also involved in this pathway. Four non-synonymous mutations were found in $X P D$ in the TCGA HCC cohort. The biological effect of these mutations and their impact on HCC patients regarding their response to chemotherapeutic drugs and OS is not known. However, in bladder cancer, nonsynonymous mutations in XPD have been associated with sensitivity to cisplatin ${ }^{[137]}$.

Mechanisms involved in the repairing of double-strand breaks, such as HR and NHEJ, are also important in the response to anticancer drugs ${ }^{[138]}$. XRCC4-like factor $(X L F)$ is a core member of NHEJ pathway required 
for the double stranded end joining. Somatic mutations in XLF gene occur at a very low frequency in HCC tumors. However, both in vitro and in vivo experiments have demonstrated that XLF knockdown confers sensitivity to drug chemotherapy, suggesting that XLF-mediated increase in NHEJ activity can play a role among mechanisms of chemoresistance in $\mathrm{HCC}^{[139]}$.

The frequency of somatic mutations in DNA repair genes with clinical impact in CCA is unknown. Nevertheless, the multicenter retrospective study of CCA patients mentioned above also reported enhanced OS of CCA patients harboring somatic mutations suspected to be pathogenic in BRCA1/2 when treated with platinum-based therapy ${ }^{[132]}$

\section{Survival pathways and apoptosis (MOC-5)}

Most pharmacological regimens currently used in the clinical treatment of cancer are based on the activation of apoptosis in cancer cells. Therefore, impairment of the involved machinery not only results in an uncontrolled cell growth, but also confers resistance to chemotherapy. The lack of response to anticancer drugs may be caused by deregulated expression and the appearance of loss-of-function mutations in proapoptotic factors (MOC-5a) or be due to an aberrant activation of anti-apoptotic proteins (MOC-5b) ${ }^{[39]}$. Somatic mutations affecting MOC-5a and MOC-5b genes in PLC are listed in Tables 7 and 8, respectively.

\section{Alteration in the expression and/or function of pro-apoptotic factors (MOC-5a)}

The TP53 gene encodes p53, which plays a key role as a tumor suppressor in several processes in response to cellular stress signals, regulating the transcription of many genes involved in cell cycle arrest, apoptosis, senescence, DNA repair and maintenance of genomic stability, among others. TP53 is one of the most frequently mutated genes in HCC $(25 \%-30 \%)^{[140]}$. Most of these mutations affect the DNA-binding domain of the protein, reducing its binding affinity to specific sequences of target genes. Cells harboring nonfunctional protein are less likely to induce apoptosis and, therefore, more resistant to DNA damage caused by chemotherapy ${ }^{[141]}$, which has clinical consequences in HCC patients ${ }^{[142]}$. A very common TP53 missense mutation in HCC is c.747G>T (p.Arg249Ser), whose incidence has been related to exposure to aflatoxin ${ }^{[143]}$. In a study carried out in 409 HCC patients, c.747G $>$ T (p.Arg249Ser) and c.469G>T (p.Val157Phe) mutations have been associated with poorer prognosis ${ }^{[143]}$. Another p53 mutation, c.743G>A (p.Arg248Gln), induces resistance to doxorubicin and paclitaxel in HCC. Cells harboring that mutation display enhanced expression of $\mathrm{MDR} 1^{[144]}$, which is a known to be able to export both drugs.

Transcription factors related to p53, such as p63 and p73 are expressed as several isoforms due to alternative splicing. Although TAp63 and TAp73 isoforms are considered as tumor suppressors with pro-apoptotic activity ${ }^{[145,146]}, \mathrm{N}$-terminal truncated isoforms, $\Delta \mathrm{Np} 63$ and $\Delta \mathrm{Np} 73$, display anti-apoptotic activity and stimulate proliferation. TAp63 and TAp73 down-regulation, and $\Delta \mathrm{Np} 63$ and $\Delta \mathrm{Np} 73$ overexpression have been found in HCC and they are related to shorter OS and tumor recurrence ${ }^{[147]}$. In addition, in vitro studies in HCC cells revealed that $\triangle \mathrm{Np} 63$ isoform confers resistance to doxorubicin and mitoxantrone through the inhibition of factors involved in mitochondrial apoptosis pathways ${ }^{[148]}$.

TP53 is also frequently mutated in $\mathrm{CCA}^{[149]}$. High expression of the truncated $\Delta \mathrm{N}$ isoform $\Delta 133 \mathrm{p} 53$, observed in CCA tissues, has been correlated with poor clinical outcome in patients suffering from this PLC ${ }^{[150]}$. Moreover, $\triangle 133 \mathrm{p} 53$ isoform expression is increased in 5-FU-resistant CCA cells ${ }^{[151]}$. On the other hand, the presence of mutations in TP53 and $C_{5} \mathrm{KN}_{2} \mathrm{~A}$ genes has been associated with poor prognosis in advanced CCA patients receiving a combination of gemcitabine and platinum-derived drugs as first-line therapy ${ }^{[152]}$.

Low levels of the pro-apoptotic factor TAp73 contribute to chemoresistance in CCA. Thus, TP73 expression is decreased in 5-FU-resistance CCA cell lines ${ }^{[153]}$. Deregulation of other pro-apoptotic proteins influences the response to anticancer drugs commonly used in CCA treatment. For example, decreased expression of 
Table 7. Somatic (S) mutations affecting coding (c) and non-coding ( $\mathrm{nc}$ ) regions of pro-apoptotic genes in primary liver cancer

\begin{tabular}{|c|c|c|c|c|c|c|c|c|c|}
\hline Gene & Protein & $\begin{array}{c}\text { Genetic } \\
\text { mutation }\end{array}$ & G/S & Region & Protein mutation & $\begin{array}{c}\text { Functional } \\
\text { consequences }\end{array}$ & $\begin{array}{c}\text { Clinical } \\
\text { consequences }\end{array}$ & Studies & References \\
\hline CASP8 & Caspase-8 & $\begin{array}{l}\text { c.1225_1226 } \\
\text { delTG }\end{array}$ & S & c & Val410Phefs`28. & Loss of function & $\begin{array}{l}\text { Probably } \\
\text { chemoresistance }\end{array}$ & HCC patients & [154] \\
\hline \multirow[t]{7}{*}{ CDKN2A } & CDKN2A & c. $248 \mathrm{G}>\mathrm{A}$ & S & c & His83Tyr & Moderate & Poor prognosis & HCC patients & [119] \\
\hline & & $\begin{array}{l}\text { g.21971148_ } \\
\text { 21971155del }\end{array}$ & S & c & Ala68Glufs`49 & High & Poor prognosis & HCC patients & [119] \\
\hline & & c. $263 C>A$ & S & c & Glu88* & High & Poor prognosis & HCC patients & [119] \\
\hline & & g.21974672del & $S$ & c & Gly52Valfs`77 & High & Poor prognosis & HCC patients & [119] \\
\hline & & $\begin{array}{l}\text { g.21974711__ } \\
\text { 21974728del }\end{array}$ & S & c & $\begin{array}{l}\text { Glu33_Asn } \\
\text { 39delinsAsp }\end{array}$ & High & Poor prognosis & HCC patients & [119] \\
\hline & & c. $72 C>G$ & S & c & Arg24Pro & Moderate & Poor prognosis & HCC patients & [119] \\
\hline & & c.36G $>\mathrm{T}$ & S & c & Ser12* & High & Poor prognosis & HCC patients & [119] \\
\hline \multirow[t]{9}{*}{ RB1 } & RB1 & c. $381 \mathrm{~A}>\mathrm{T}$ & S & c & Ser127_splice & ND & $\begin{array}{l}\text { Early recurrence } \\
\text { after resection }\end{array}$ & HCC patients & [155] \\
\hline & & c. $508 \mathrm{G}>\mathrm{T}$ & S & c & Glu170* & Loss of function & $\begin{array}{l}\text { Early recurrence } \\
\text { after resection }\end{array}$ & HCC patients & [155] \\
\hline & & c.646delT & S & c & Phe216fs & ND & $\begin{array}{l}\text { Early recurrence } \\
\text { after resection }\end{array}$ & HCC patients & [155] \\
\hline & & c. $763 C>T$ & S & c & Arg255* & Loss of function & $\begin{array}{l}\text { Early recurrence } \\
\text { after resection }\end{array}$ & HCC patients & [155] \\
\hline & & c. $979 A>T$ & S & c & Lys327* & Loss of function & $\begin{array}{l}\text { Early recurrence } \\
\text { after resection }\end{array}$ & HCC patients & [155] \\
\hline & & c. $1421 G>A$ & S & c & Ser474Asn & ND & $\begin{array}{l}\text { Early recurrence } \\
\text { after resection }\end{array}$ & HCC patients & [155] \\
\hline & & c. $1472 T>C$ & S & c & Leu491Pro & ND & $\begin{array}{l}\text { Early recurrence } \\
\text { after resection }\end{array}$ & HCC patients & [155] \\
\hline & & c. $1654 C>T$ & S & c & Arg552* & Loss of function & $\begin{array}{l}\text { Early recurrence } \\
\text { after resection }\end{array}$ & $\mathrm{HCC}$ patients & [155] \\
\hline & & c.2120delC & S & c & Ser707fs & ND & $\begin{array}{l}\text { Early recurrence } \\
\text { after resection }\end{array}$ & HCC patients & [155] \\
\hline \multirow[t]{4}{*}{ TP53 } & p53 & c.747G > T & S & c & Arg249Ser & Loss of function & Poor prognosis & HCC patients & [143] \\
\hline & & c. $469 \mathrm{G}>\mathrm{T}$ & S & c & Val157Phe & Loss of function & Poor prognosis & HCC patients & [143] \\
\hline & & c. $743 \mathrm{G}>\mathrm{A}$ & S & c & Arg248GIn & Loss of function & $\begin{array}{l}\text { Doxorubicin } \\
\text { resistance }\end{array}$ & $\mathrm{HCC}$ in vitro & [144] \\
\hline & & & S & c & $\begin{array}{l}\text { 1-132del } \\
\text { (truncated variant } \\
\Delta 133 p 53 \text { ) }\end{array}$ & $\begin{array}{l}\text { Dominant } \\
\text { negative }\end{array}$ & $\begin{array}{l}\text { Poor outcome, } \\
5 \text {-FU resistance }\end{array}$ & CCA patients & $\begin{array}{l}{[150]} \\
{[151]}\end{array}$ \\
\hline TP63 & p63 & & S & c & $\begin{array}{l}\text { 1-62del } \\
\text { (truncated variant } \\
\Delta \text { Np63) }\end{array}$ & $\begin{array}{l}\text { Gain of function } \\
\text { (antiapoptotic- } \\
\text { effect) }\end{array}$ & $\begin{array}{l}\text { Doxorubicin and } \\
\text { mitoxantrone } \\
\text { resistance. } \\
\text { Shorter OS }\end{array}$ & HCC patients & $\begin{array}{l}{[147]} \\
{[148]}\end{array}$ \\
\hline TP73 & p73 & & S & c & $\begin{array}{l}1-72 \mathrm{del} \\
\text { (truncated variant } \\
\Delta \mathrm{Np} 73 \text { ) }\end{array}$ & $\begin{array}{l}\text { Gain of function } \\
\text { (antiapoptotic- } \\
\text { effect) }\end{array}$ & Shorter OS & HCC patients & [147] \\
\hline
\end{tabular}

Data obtained from cBioportal database and referred literature. Functional consequences are based on VEP (Variant Effect Predictor; https://www.ensembl.org/vep) impact: High means that the variant is supposed to cause a high disruptive impact in the protein, which is likely to cause loss of function; Moderate means that the variant may be not disruptive, but results in a decrease effectiveness of the encoded protein; Modifier is usually referred to non-coding variants, whose impact is difficult to determine, although they can be involved in transcription or splicing changes. CCA: cholangiocarcinoma; HCC: hepatocellular carcinoma; 5-FU: 5-fluorouracil; OS: overall survival; ND: not determined

Bax, which participates in the intrinsic apoptotic pathway, has been reported in gemcitabine-resistant cell lines ${ }^{[156]}$. However, Bax mutations have not been described in CCA samples.

Somatic mutations in several genes involved in the cell cycle regulation, including CDKN2A y RB1, have been identified. The presence of inactivating mutations in CDKN2A, a cyclin-dependent kinase inhibitor, has been associated with poorer prognosis in $\mathrm{HCC}^{[119]}$. In the case of $R B 1$, a relationship between mutations in this gene and early recurrence of HCC after resection has been found ${ }^{[155]}$. Damaging mutations appearing in genes coding for other checkpoint proteins, which might be involved in carcinogenesis, have been 
Table 8. Somatic (S) mutations affecting coding (c) and non-coding (nc) regions of anti-apoptotic genes in primary liver cancer

\begin{tabular}{|c|c|c|c|c|c|c|c|c|c|}
\hline Gene & Protein & $\begin{array}{c}\text { Genetic } \\
\text { mutations }\end{array}$ & $\mathbf{G} / \mathbf{S}$ & Region & Protein mutation & $\begin{array}{c}\text { Functional } \\
\text { consequences }\end{array}$ & $\begin{array}{c}\text { Clinical } \\
\text { consequences }\end{array}$ & Studies & References \\
\hline \multirow[t]{7}{*}{ CTNNB1 } & \multirow[t]{7}{*}{$\begin{array}{l}\text { Catenine } \\
\text { beta-1 }\end{array}$} & $\begin{array}{l}c .95 A>G / T \\
c .94 G>T \\
c .94 G>C\end{array}$ & $\mathrm{~S}$ & c & $\begin{array}{l}\text { Asp32Gly/Val } \\
\text { Asp32Tyr } \\
\text { Asp32His }\end{array}$ & $\begin{array}{l}\text { Gain-of-function } \\
\text { ND }\end{array}$ & $\begin{array}{l}\text { Controversial } \\
\text { ND }\end{array}$ & $\begin{array}{l}\text { HCC patients } \\
\text { HCC patients }\end{array}$ & $\begin{array}{l}{[157,158]} \\
{[159,160]} \\
d b E M T\end{array}$ \\
\hline & & $\begin{array}{l}\text { c. } 98 \mathrm{C}>\mathrm{G} / \mathrm{A} / \mathrm{T} / \\
\mathrm{c} .97 \mathrm{~T}>\mathrm{C} / \mathrm{G}\end{array}$ & $S$ & c & $\begin{array}{l}\text { Ser33Cys/Tyr/Phe/Pro/ } \\
\text { Ala }\end{array}$ & Gain-of-function & Controversial & HCC patients & [157-160] \\
\hline & & c.99_113del15 & S & c & $\begin{array}{l}\text { Gly34_Gly38delGlylle } \\
\text { HisSerGly }\end{array}$ & ND & ND & $\mathrm{HCC}$ & dbEMT \\
\hline & & c. $1202 \mathrm{~T}>\mathrm{A}$ & & & Leu401His & ND & ND & $\mathrm{HCC}$ & $\mathrm{dbEMT}$ \\
\hline & & $\begin{array}{l}\text { c. } 110 \mathrm{C}>\mathrm{G} / \mathrm{A} / \mathrm{T} / \\
\text { c. } 109 \mathrm{~T}>\mathrm{C} / \mathrm{G}\end{array}$ & S & c & $\begin{array}{l}\text { Ser37Cys/Tyr/Phe/Pro/ } \\
\text { Ala }\end{array}$ & Gain-of-function & Controversial & HCC patients & [157-160] \\
\hline & & $\begin{array}{l}\text { c. } 121 \mathrm{~A}>\mathrm{G} / \\
\text { c. } 122 \mathrm{C}>\mathrm{T} / \mathrm{A}\end{array}$ & $S$ & c & Thr41Ala/Ile/Asn & Gain-of-function & Controversial & HCC patients & [157-160] \\
\hline & & $\begin{array}{l}\text { c. } 134 \mathrm{C}>\mathrm{G} / \mathrm{A} / \mathrm{T} / \\
\text { c. } 133 \mathrm{~T}>\mathrm{C} / \mathrm{G}\end{array}$ & S & c & $\begin{array}{l}\text { Ser45Cys/Tyr/Phe/Pro/ } \\
\text { Ala }\end{array}$ & Gain-of-function & Controversial & HCC patients & [157-160] \\
\hline \multirow[t]{3}{*}{ JAK1 } & \multirow[t]{3}{*}{ JAK1 } & $\begin{array}{l}\text { c.1932G }>\mathrm{T} / \\
\text { c.1933G }>\mathrm{T} \\
\text { (tandem } \\
\text { mutation) }\end{array}$ & S & c & Gln644His/Val645Phe & Gain-of-function & ND & $\begin{array}{l}\mathrm{HCC} \text { in vitro } \\
\text { and patients }\end{array}$ & [161] \\
\hline & & c. $2108 \mathrm{G}>\mathrm{T}$ & $S$ & c & Ser703Ile & Gain-of-function & ND & $\begin{array}{l}\mathrm{HCC} \text { in vitro } \\
\text { and patients }\end{array}$ & [161] \\
\hline & & c. $2185 \mathrm{~A}>\mathrm{T}$ & $S$ & c & Ser729Cys & Gain-of-function & ND & $\begin{array}{l}\text { HCC in vitro } \\
\text { and patients }\end{array}$ & [161] \\
\hline KRAS & K-Ras & $\begin{array}{l}\text { c. } 35 \mathrm{G}>\mathrm{T} / \mathrm{A} / \\
\text { c. } 34 \mathrm{G}>\mathrm{T} / \mathrm{A}\end{array}$ & S & c & Gly12Val/Asp/Cys/Ser & Gain-of-function & $\begin{array}{l}\text { Reduced } \\
\text { survival }\end{array}$ & CCA patients & {$[162,132]$} \\
\hline \multirow[t]{4}{*}{ mtDNA } & $\operatorname{cox} 1$ & m.T6115C & S & c & Met71Thr & Loss-of-function & ND & HCC patients & [164] \\
\hline & ATP8 & m.G8387A & S & c & Val8Met & Loss-of-function & ND & HCC patients & [164] \\
\hline & ND5 & m.G13121A & S & c & Arg262His & Loss-of-function & ND & HCC patients & [164] \\
\hline & ND6 & m.T14180C & S & c & Tyr165Cys & Loss-of-function & ND & HCC patients & [164] \\
\hline \multirow[t]{4}{*}{ PIK3CA } & \multirow{4}{*}{$\begin{array}{l}\text { PI3K } \\
\text { p110 } \alpha \\
\text { subunit }\end{array}$} & $\begin{array}{l}\text { c.3204_320 } \\
\text { 5ins A }\end{array}$ & S & c & Asn1068fs ${ }^{\star} 4$ & Gain-of-function & ND & HCC patients & cosmic \\
\hline & & c. $3140 A>G$ & S & c & His1047Arg & Gain-of-function & ND & HCC patients & cosMIC \\
\hline & & c. $1624 G>A$ & S & c & Glu542Lys & Gain-of-function & ND & HCC patients & COSMIC \\
\hline & & c. $1633 \mathrm{G}>\mathrm{A}$ & $\mathrm{S}$ & c & Glu545Lys & Gain-of-function & ND & HCC patients & cosMIC \\
\hline PTEN & PTEN & $\begin{array}{l}\text { Loss of hetero } \\
\text { zygosity at } 10 \mathrm{q} 23\end{array}$ & S & c & & $\begin{array}{l}\text { Lower } \\
\text { expression }\end{array}$ & ND & HCC patients & {$[165,166]$} \\
\hline \multirow[t]{2}{*}{ TSC1 } & \multirow[t]{2}{*}{ TSC1 } & c.2278delA & S & c & Arg760fs & Loss-of-function & ND & HCC patients & [167] \\
\hline & & c.965dup T & S & c & Met322fs & Loss-of-function & ND & HCC patients & [167] \\
\hline \multirow[t]{10}{*}{ TSC2 } & \multirow[t]{10}{*}{ TSC2 } & c. $3400 \mathrm{G}>\mathrm{A}$ & S & c & Gly1134Ser & Loss-of-function & ND & HCC patients & [167] \\
\hline & & $\begin{array}{l}\text { c. } 4653 \_4655 \\
\text { delAGA }\end{array}$ & S & c & 1551_1552del & Loss-of-function & ND & HCC patients & [167] \\
\hline & & c. $3050 C>G$ & S & c & Thr1017Arg & Loss-of-function & ND & HCC patients & [167] \\
\hline & & c. $2355 \mathrm{G}>\mathrm{T}$ & S & c & Gln785His & Loss-of-function & ND & HCC patients & [167] \\
\hline & & c. $4129 \mathrm{C}>\mathrm{T}$ & S & c & $\mathrm{G} \ln 1377^{\star}$ & Loss-of-function & ND & HCC patients & [167] \\
\hline & & c. $4129 C>T$ & S & c & $\mathrm{G} \ln 1377^{\star}$ & Loss-of-function & $\begin{array}{l}\text { Rapamycin } \\
\text { sensitivity }\end{array}$ & $\begin{array}{l}\mathrm{HCC} \text { in vitro / } \\
\mathrm{HCC} \text { patients }\end{array}$ & [167] \\
\hline & & c. $173 C>T$ & S & c & Gln63* & Loss-of-function & $\begin{array}{l}\text { Rapamycin } \\
\text { sensitivity }\end{array}$ & $\begin{array}{l}\mathrm{HCC} \text { in vitro / } \\
\mathrm{HCC} \text { patients }\end{array}$ & [167] \\
\hline & & c. $482-2 A>T$ & S & $\mathrm{nc}$ & intron 5 splicing acceptor & Loss-of-function & ND & HCC patients & [167] \\
\hline & & c. $2355+1 G>T$ & S & $\mathrm{nc}$ & intron 21 splicing donor & Loss-of-function & ND & HCC patients & [167] \\
\hline & & c.1947-2delA & S & $\mathrm{nc}$ & $\begin{array}{l}\text { intron } 18 \text { splicing } \\
\text { acceptor }\end{array}$ & Loss-of-function & ND & HCC patients & [167] \\
\hline
\end{tabular}

Data obtained from COSMIC database, dbEMT and referred literature. CCA: cholangiocarcinoma; HCC: hepatocellular carcinoma; ND: not determined

identified $^{[119]}$. However, no clinical consequences for these HCC patients have been reported. In contrast, a frameshift mutation in CDKN1A encoding a truncated protein which lacks the ability to interact with its targets has been found to confer resistance to paclitaxel in breast cancer cells ${ }^{[168]}$. 
Caspase 8 plays a key role in signal transduction within the extrinsic apoptotic pathway. Somatic mutations with loss-of-function affecting this protein have been associated with the resistance to drugs whose mechanism of action includes apoptosis activation ${ }^{[169]}$. In a study of 69 HCC patients, 9 of them had the same alteration in the caspase 8 gene (CASP8), c.1225_1226delTG, a frameshift mutation with two basepair deletion resulting in a defective protein with a shorter p10 protease subunit ${ }^{[154]}$. Mutations affecting p10 subunit of procaspase- 8 have been reported to promote unresponsiveness to chemotherapy in other cancers, such as acute myeloid leukemia ${ }^{[170]}$. Whether these mutations are also involved in HCC chemoresistance is not known.

Alterations in anti-apoptotic/pro-survival factors (MOC-5b)

Aberrant expression and/or activating mutations in anti-apoptotic factors as well as constitutive activation of pro-survival signaling pathways, such as PI3K/AKT, Ras/Raf/MAPK/ERK/MEK or JAK/STAT, lead to an uncontrolled cell proliferation and evasion of apoptosis in cancer cells, which contributes to tumor progression and reduces effectiveness of chemotherapeutic drugs.

The PI3K/PTEN/AKT/mTOR pathway, commonly altered in HCC, is associated with poor prognosis ${ }^{[171]}$. The frequency of PIK3CA mutations in HCC is controversial, ranging from 0 to $36 \%$ of HCC cases depending on the population studied ${ }^{[172,173]}$. Some of the most recurrent PIK3CA mutations in HCC samples according to the data from COSMIC, such as c.3204_3205insA (p.Asn1068fs ${ }^{*}$ ) and c.3140A>G (p.His1047Arg) are oncogenic $^{[174,175]}$. Other mutations described in HCC, such as c.1624G>A (p.Glu542Lys) and c.1633G>A (p.Glu545Lys), affecting the PIK helical domain of the protein confer gain-of-function ${ }^{[175]}$. Although PIK3CA mutations have not been directly related to chemoresistance in HCC, an in vitro assay has reported PIK3CA overexpression in sorafenib-resistant HCC cells ${ }^{[176]}$.

The tumor suppressor gene PTEN is the major negative regulator of PI3K/AKT/mTOR pathway. Therefore, alterations leading to PTEN loss-of-function could induce the activation of this pathway. Even though PTEN mutations are uncommon in HCC, somatic loss of heterozygosity of PTEN allele has been found in 20\%$30 \%$ of HCC cases $^{[165,166]}$. Moreover, PTEN down-regulation may be also caused by epigenetic alterations ${ }^{[177]}$. These changes are clinically relevant because PTEN expression has been found to be decreased in sorafenibresistant $\mathrm{HCC}$ cells ${ }^{[176]}$. Therefore, activation of PI3K/AKT/mTOR pathway due to impaired PIK3CA and PTEN genes may play a key role among MOC accounting for the lack of response of HCC patients to sorafenib. At this respect, several preclinical and clinical studies have been carried out to evaluate the efficacy of inhibitors targeting PI3K/PTEN/Akt/mTOR pathway. Some of them have shown promising results ${ }^{[178]}$. For instance, inactivating mutations in TSC1/2 genes have been found both in HCC cell lines and clinical specimens, resulting in an impairment of mTOR signaling. However, HCC cells harboring these mutations were sensitive to rapamycin, an mTOR inhibitor ${ }^{[167]}$. TSC2-null HCC cell lines have also shown to be sensitive to everolimus, another mTOR inhibitor, and HCC patients with low expression of TSC2 treated with everolimus have higher OS rates ${ }^{[179]}$.

Regarding JAK/STAT signaling pathway in HCC tumors, somatic mutations mainly affecting domains of JAK1 (pseudo-kinase and tyrosine kinase) have been identified, which lead to constitutively activated JAK/ STAT signaling ${ }^{[161]}$. Since JAK/STAT pathway is involved in acquired resistance of HCC cells to sorafenib ${ }^{[180]}$, these findings suggest that mutations in JAK1 may lead to failure of sorafenib treatment due to compensatory proliferation. Thus, mutated JAK1 could be a potential target for pharmacological manipulation. Indeed, cells harboring c.2108G>T (p.Ser703Ile) variant were sensitive to ruxolitinib, a JAK1/2 inhibitor ${ }^{[181]}$.

Wnt/ $\beta$-catenin signaling pathway is frequently deregulated in HCC, leading to $\beta$-catenin accumulation in the nucleus of cancer cells ${ }^{[159]}$. Aberrant activation of this pathway is largely due to gain-of-function mutations in CTNNB1 gene, encoding $\beta$-catenin protein, which have been observed in $20 \%-40 \%$ of HCC 
samples assayed ${ }^{[182]}$. These are somatic mutations usually located in exon 3 encoding the N-terminal phosphorylation sites of $\beta$-catenin. HCC sequencing studies collected in cBioportal database reveal that most frequent mutations occur in Ser/Thr phosphorylation residues (codons 33, 37,41 and 45) and in codon 32. The clinical implication of these mutations is controversial. Some studies have associated the presence of CNNTB1 mutations in HCC with better $\mathrm{OS}^{[157,158]}$, whereas others have linked these mutations to tumor progression and poor prognosis ${ }^{[159,160]}$.

The insulin-like growth factor (IGF) signaling cascade is also involved in cell growth and survival, and its activation plays an important role in the resistance of HCC to TKIs ${ }^{[183,184]}$. An in vivo assay has demonstrated the presence of elevated IG2F levels as one of the major mechanisms of acquired resistance to sorafenib in $\mathrm{HCC}^{[184]}$. In addition, it has been shown that c.747G>T (p.Arg249Ser) mutation in p53, which is very common in aflatoxin-induced HCC, is accompanied by enhanced expression of IGF2 and type 1 IGF receptor ${ }^{[185]}$. This suggests a possible link between this p53 mutation and the resistance of HCC to TKIs.

The presence of alterations in Ras/Raf/MEK/MAPK/ERK pathway may play an important role in the response of CCA to chemotherapy. Mutations in KRAS gene have been observed in different subtypes of CCA, mainly affecting codon 12, such as c.35G >T (p.Gly12Val), c.35G >A (p.Gly12Asp), c.34G $>\mathrm{T}$ (p.Gly12Cys) and c.34G $>A$ (p.Gly12Ser), with variable incidence depending on the population under study ${ }^{[162,186,187]}$. These mutations have oncogenic potential, leading to constitutive stimulation of K-Ras and, consequently, activation of downstream signaling effectors ${ }^{[188]}$. Several studies have reported a reduced survival of CCA patients with mutations in K-Ras codon $12^{[162,189]}$. These mutations conferred resistance to everolimus in CCA cells ${ }^{[163]}$.

Both somatic mutations and reduced copy number of mitochondrial DNA ( $\mathrm{mtDNA}$ ) have been found in a large proportion of HCC tumors ${ }^{[164,190]}$. Some of these mutations affect coding regions and result in amino acid substitution or premature stop codon in polypeptides of respiratory complexes, which presumably leads to mitochondrial dysfunction. In tumor cells, this impairment results in altered reactive oxygen species (ROS) production, which can promote activation of survival pathways or changes in the expression of antiapoptotic factors, eventually leading to an adverse impact on the response to chemotherapy. This is consistent with the finding that mtDNA depletion in HCC cells promotes resistance to 5-FU ${ }^{[164]}$.

\section{NOVEL MECHANISMS AFFECTING CHEMOTHERAPY EFFICACY}

\section{Autophagy and changes in tumor microenvironment}

Recent evidences have shown that tumor microenvironmental stress-induced autophagy may contribute in part to the development of chemoresistance ${ }^{[191]}$. Thus, in HCC cells treated with oxaliplatin autophagy is activated, which favors cell survival ${ }^{[192]}$. Moreover, oxygen deficiency triggers the activation of hypoxiaspecific transcription factors, which regulates the expression of genes that increase cancer cell survival and drug resistance ${ }^{[193]}$. In addition, these factors are master regulators of the expression of genes involved in the phenotypic epithelial-mesenchymal transition (EMT), cell migration (MMP2), homing (CXCR4) and the establishment of the pre-metastatic niche $(L O X)^{[193]}$. Somatic mutations in these genes have been described in HCC, although their relevance in protein function remains unknown [Table 9].

In the case of CCA, interleukins, like IL-6, released by immune cells present in the tumor microenvironment, particularly macrophages, can confer resistance to toxic compounds and promote tumor growth. Targeting tumor microenvironment rather than CCA cells directly may lead to novel therapeutic strategies to treat this cancer ${ }^{[194]}$. In the case of HCC, higher expression of IL-6 also seems to be a key player. Moreover, IL- 6 knockdown in HCC cells increased their sensitivity to sorafenib ${ }^{[195]}$. Whether several somatic mutations described in IL-6 gene [Table 9] have any influence in MOC-6 of PLC is poorly understood. 
Table 9. Somatic (S) mutations affecting coding (c) and non-coding (nc) regions of genes related to tumor microenvironment in primary liver cancer

\begin{tabular}{|c|c|c|c|c|c|c|c|c|c|}
\hline Gene & Protein & $\mathbf{G} / \mathbf{S}$ & Region & Genetic mutations & Protein mutations & $\begin{array}{c}\text { Functional } \\
\text { consequences }\end{array}$ & $\begin{array}{c}\text { Clinical } \\
\text { consequences }\end{array}$ & Studies & References \\
\hline \multirow[t]{3}{*}{ IL6 } & IL6 & $S$ & c & c.179T>A & Ile60Asn & Moderate & Neutral & TCGA-LIHC & TCGA \\
\hline & & $\begin{array}{l}S \\
S\end{array}$ & $\begin{array}{l}\mathrm{c} \\
\mathrm{nc}\end{array}$ & $\begin{array}{l}\text { c. } 83 C>T \\
\text { c. } 20-6 C>T\end{array}$ & $\begin{array}{l}\text { Ala28Val } \\
\text { Splice region variant }\end{array}$ & $\begin{array}{l}\text { Moderate } \\
\text { Modifier }\end{array}$ & $\begin{array}{l}\text { Neutral } \\
\text { Neutral }\end{array}$ & $\begin{array}{l}\text { TCGA-LIHC } \\
\text { TCGA-LIHC }\end{array}$ & $\begin{array}{l}\text { TCGA } \\
\text { TCGA }\end{array}$ \\
\hline & & S & $\mathrm{nc}$ & c. $243+169 T>G$ & Intron & Modifier & ND & TCGA-LIHC & TCGA \\
\hline \multirow[t]{3}{*}{ MMP2 } & MMP2 & $S$ & c & c. $648 \mathrm{G}>\mathrm{T}$ & Lys216Asn & Moderate & ND & TCGA-LIHC & TCGA \\
\hline & & S & c & c. $1160 C>G$ & Pro387Arg & Moderate & ND & TCGA-CHOL & TCGA \\
\hline & & $\begin{array}{l}S \\
S\end{array}$ & $\begin{array}{l}\mathrm{c} \\
\mathrm{nc}\end{array}$ & $\begin{array}{l}\text { c. } 85 G>A \\
\text { c. }-75-3345 G>A\end{array}$ & $\begin{array}{l}\text { Ala29Thr } \\
\text { Intron }\end{array}$ & $\begin{array}{l}\text { Moderate } \\
\text { Modifier }\end{array}$ & $\begin{array}{l}\text { Pathogenic } \\
\text { Pathogenic }\end{array}$ & $\begin{array}{l}\text { TCGA-LIHC } \\
\text { TCGA-LIHC }\end{array}$ & $\begin{array}{l}\text { TCGA } \\
\text { TCGA }\end{array}$ \\
\hline CXCR4 & CXCR4 & $\begin{array}{l}S \\
S\end{array}$ & $\begin{array}{l}\mathrm{c} \\
\mathrm{nc}\end{array}$ & $\begin{array}{l}\text { c. } 664 A>T \\
\text { c. }-55 C>A\end{array}$ & $\begin{array}{l}\text { Ile226Phe } \\
\text { 5'UTR }\end{array}$ & $\begin{array}{l}\text { Moderate } \\
\text { Modifier }\end{array}$ & $\begin{array}{l}\text { Pathogenic } \\
\text { ND }\end{array}$ & $\begin{array}{l}\text { TCGA-LIHC } \\
\text { TCGA-LIHC }\end{array}$ & $\begin{array}{l}\text { TCGA } \\
\text { TCGA }\end{array}$ \\
\hline LOX & LOX & $\begin{array}{l}S \\
S \\
S\end{array}$ & $\begin{array}{l}\mathrm{c} \\
\mathrm{c} \\
\mathrm{nc}\end{array}$ & $\begin{array}{l}\text { c. } 1144 C>T \\
\text { c. } 850 T>A \\
\text { c. }{ }^{\star} 42 T>A\end{array}$ & $\begin{array}{l}\text { Pro382Ser } \\
\text { Tyr284Asn } \\
3^{\prime} \cup T R\end{array}$ & $\begin{array}{l}\text { Moderate } \\
\text { Moderate } \\
\text { Modifier }\end{array}$ & $\begin{array}{l}\text { Pathogenic } \\
\text { Pathogenic } \\
\text { Pathogenic }\end{array}$ & $\begin{array}{l}\text { TCGA-LIHC } \\
\text { TCGA-LIHC } \\
\text { TCGA-LIHC }\end{array}$ & $\begin{array}{l}\text { TCGA } \\
\text { TCGA } \\
\text { TCGA }\end{array}$ \\
\hline
\end{tabular}

Data obtained from TCGA database. Functional consequences are based on VEP (Variant Effect Predictor; https://www.ensembl.org/vep) impact: High means that the variant is supposed to cause a high disruptive impact in the protein, which is likely to cause loss of function; Moderate means that the variant may be not disruptive, but results in a decrease effectiveness of the encoded protein; Modifier is usually referred to non-coding variants, whose impact is difficult to determine, although they can be involved in transcription or splicing changes. ND: not determined; TCGA: the cancer genome atlas; TCGA-LIHC: the cancer genome atlas - liver hepatocellular carcinoma; TCGA$\mathrm{CHOL}$ : the cancer genome atlas - cholangiocarcinoma

\section{EMT-associated chemoresistance}

EMT is the mechanism that leads to a transient and reversible de-differentiation of epithelial cells to a mesenchymal phenotype ${ }^{[196]}$. Changes occurred during EMT are evidenced by the loss of epithelial markers, such as E-cadherin ${ }^{[197]}$ and the increased expression of mesenchymal proteins such as $\mathrm{N}$-cadherin, a-smooth muscle actin (a-SMA), fibroblast-specific protein (FSP-1) and EMT-transcription factors Snail (SNA1), Slug (SNA2), Twist and ZEB ${ }^{[196]}$. Among them, Snail is the most prominent inducer of EMT in $\mathrm{HCC}^{[198]}$. Although several somatic mutations in genes involved in EMT have been described [Table 10], the actual role in HCC chemoresistance of the resulting variants is not known.

In healthy biliary epithelium, E-cadherin is located at the plasma membrane of cholangiocytes, whereas in malignant CCA cells down-regulation and cytoplasmic internalization of E-cadherin occurs. Mutations and epigenetic silencing by the hypermethylation of E-cadherin gene $(\mathrm{CDH} 1)$ are some of the mechanisms accounting for its down-regulation, which correlates with poor tumor differentiation and metastasis ${ }^{[199-204]}$. Interestingly, CCA cells exhibiting mesenchymal traits are more resistant to gemcitabine than those characterized by a prominent epithelial phenotype ${ }^{[205]}$. In the case of HCC, the overexpression of nestin, a type VI intermediate filament protein, has been associated with EMT and chemoresistance ${ }^{[206]}$.

Alternative splicing may also affect EMT. The functional consequences of differential splicing in EMT is illustrated by p120 catenin, the adhesion protein cluster of differentiation 44 (CD44), and FGFR2. Many changes affecting alternative splicing during EMT come from the rapid down-regulation of two RNAbinding proteins: epithelial splicing regulatory protein 1 (ESRP1) and ESRP2. Their down-regulation results in the generation of pro-mesenchymal protein isoforms that lead to alterations in adhesion, motility and signaling pathways ${ }^{[207-209]}$.

\section{CONCLUSION}

The information summarized in the present review clearly shows that germline and somatic mutations in genes involved in MOC play an important role in the overall response of HCC and CCA to chemotherapy. Although a remarkable advance in the identification and characterization of the functional consequences of these mutations has been achieved in the last decade it is evident that our current knowledge of this problem 
Table 10. Somatic (S) mutations affecting coding (c) and non-coding $(\mathrm{nc})$ regions of genes related to epithelial-mesenchymal transition (EMT) in primary liver cancer

\begin{tabular}{|c|c|c|c|c|c|c|c|c|c|}
\hline Gene & Protein & $\begin{array}{c}\text { Genetic } \\
\text { mutations }\end{array}$ & $\mathbf{G} / \mathbf{S}$ & Region & $\begin{array}{c}\text { Protein } \\
\text { mutations }\end{array}$ & $\begin{array}{c}\text { Functional } \\
\text { consequences }\end{array}$ & $\begin{array}{c}\text { Clinical } \\
\text { consequences }\end{array}$ & Studies & References \\
\hline VIM & VIM & $\begin{array}{l}\text { c. } 1024 C>A \\
\text { c.1348A }>G\end{array}$ & $\begin{array}{l}\mathrm{S} \\
\mathrm{S}\end{array}$ & $\begin{array}{l}\mathrm{c} \\
\mathrm{c}\end{array}$ & $\begin{array}{l}\text { Arg342Ser } \\
\text { Arg450Gly }\end{array}$ & $\begin{array}{l}\text { ND } \\
\text { ND }\end{array}$ & $\begin{array}{l}N D \\
N D\end{array}$ & $\begin{array}{l}\text { HCC patients } \\
\text { HCC patients }\end{array}$ & $\begin{array}{l}\text { dbEMT } \\
\text { dbEMT }\end{array}$ \\
\hline SMAD3 & SMAD3 & c. $425 \mathrm{G}>\mathrm{A}$ & ND & c & Arg142His & ND & ND & HCC patients & dbEMT \\
\hline HIF1A & HIF1A & c. $984 G>C$ & ND & c & Lys328Asn & ND & ND & HCC patients & dbEMT \\
\hline TGFB1 & TGF $\beta-1$ & c. $528 \mathrm{C}>\mathrm{T}$ & ND & c & Asn176Asn & ND & ND & Liver carcinoma & dbEMT \\
\hline ZEB1 & ZEB1 & $\begin{array}{l}\text { c. } 892 \mathrm{G}>\mathrm{C} \\
\text { c. } 777 \mathrm{~A}>\mathrm{T} \\
\text { c. } 1219 \mathrm{~A}>\mathrm{G} \\
\text { c. } 824 \mathrm{~A}>\mathrm{C}\end{array}$ & $\begin{array}{l}S \\
S \\
S \\
S\end{array}$ & $\begin{array}{l}\text { c } \\
\text { c } \\
c \\
c\end{array}$ & $\begin{array}{l}\text { Val298Leu } \\
\text { Leu259Phe } \\
\text { lle407Val } \\
\text { Lys275Thr }\end{array}$ & $\begin{array}{l}\text { ND } \\
\text { ND } \\
\text { ND } \\
\text { ND }\end{array}$ & $\begin{array}{l}\text { ND } \\
\text { ND } \\
\text { ND } \\
\text { ND }\end{array}$ & $\begin{array}{l}\text { HCC patients } \\
\text { Liver carcinoma } \\
\text { Liver carcinoma } \\
\text { Liver carcinoma }\end{array}$ & $\begin{array}{l}\text { dbEMT } \\
\text { dbEMT } \\
\text { dbEMT } \\
\text { dbEMT }\end{array}$ \\
\hline ZEB2 & ZEB2 & $\begin{array}{l}\text { c. } 80 A>G \\
\text { c. } 1141 A>G \\
\text { c. } 1862 T>C \\
\text { c. } 855 A>G \\
\text { c. } 2519 G>T\end{array}$ & $\begin{array}{l}S \\
N D \\
N D \\
N D \\
N D\end{array}$ & $\begin{array}{l}\text { c } \\
\text { c } \\
\text { c } \\
\text { c } \\
\text { c }\end{array}$ & $\begin{array}{l}\text { Asn27Ser } \\
\text { Met381Val } \\
\text { Val621Ala } \\
\text { Thr285Thr } \\
\text { Ser840lle }\end{array}$ & $\begin{array}{l}\text { ND } \\
\text { ND } \\
\text { ND } \\
\text { ND } \\
\text { ND }\end{array}$ & $\begin{array}{l}\text { ND } \\
\text { ND } \\
N D \\
\text { ND } \\
\text { ND }\end{array}$ & $\begin{array}{l}\text { Liver Carcinoma } \\
\text { HCC patients } \\
\text { Liver carcinoma } \\
\text { Liver carcinoma } \\
\text { Liver carcinoma }\end{array}$ & $\begin{array}{l}\text { dbEMT } \\
\text { dbEMT } \\
\text { dbEMT } \\
\text { dbEMT } \\
\text { dbEMT }\end{array}$ \\
\hline $\mathrm{CDH} 1$ & $\mathrm{CDH} 1$ & $\begin{array}{l}c .884 C>T \\
c .1027 C>T \\
c .1107 C>T \\
c .900 C>G \\
c .1019 C>T \\
c .1070 C>T \\
c .925 C>T \\
c .427 C>T\end{array}$ & $\begin{array}{l}S \\
S \\
S \\
S \\
S \\
S \\
S \\
S \\
S\end{array}$ & $\begin{array}{l}c \\
c \\
c \\
c \\
c \\
c \\
c \\
c \\
c \\
c\end{array}$ & $\begin{array}{l}\text { Thr295lle } \\
\text { Leu343Leu } \\
\text { Asn369Asn } \\
\text { lle300Met } \\
\text { Thr340Met } \\
\text { Thr357lle } \\
\text { Pro309Ser } \\
\text { Pro143Ser }\end{array}$ & $\begin{array}{l}\text { ND } \\
\text { ND } \\
\text { ND } \\
\text { ND } \\
\text { ND } \\
\text { ND } \\
\text { ND } \\
\text { ND }\end{array}$ & $\begin{array}{l}\text { ND } \\
\text { ND } \\
\text { ND } \\
\text { ND } \\
\text { ND } \\
\text { ND } \\
\text { ND } \\
\text { ND }\end{array}$ & $\begin{array}{l}\text { HCC patients } \\
\text { Bile duct cancer } \\
\text { Bile duct cancer } \\
\text { Bile duct cancer } \\
\text { Bile duct cancer } \\
\text { HCC patients } \\
\text { HCC patients } \\
\text { HCC patients }\end{array}$ & $\begin{array}{l}\text { dbEMT } \\
\text { dbEMT } \\
\text { dbEMT } \\
\text { dbEMT } \\
\text { dbEMT } \\
\text { dbEMT } \\
\text { dbEMT } \\
\text { dbEMT }\end{array}$ \\
\hline ILK & ILK & $\begin{array}{l}\text { c. } 590 C>A \\
\text { c. }{ }^{\star} 1 G>A\end{array}$ & $\begin{array}{l}S \\
S\end{array}$ & $\begin{array}{l}\mathrm{c} \\
\mathrm{nc}\end{array}$ & $\begin{array}{l}\text { Ser197Tyr } \\
\text { 3'UTR }\end{array}$ & $\begin{array}{l}\text { ND } \\
\text { Modifier }\end{array}$ & $\begin{array}{l}\text { ND } \\
\text { ND }\end{array}$ & $\begin{array}{l}\text { ND } \\
\text { TCGA-LIHC }\end{array}$ & $\begin{array}{l}\text { dbEMT } \\
\text { TCGA }\end{array}$ \\
\hline NES & Nestin & $\begin{array}{l}\text { c. } 4489 \mathrm{G}>\mathrm{T} \\
\text { c. } 2221 \mathrm{C}>\mathrm{A} \\
\mathrm{c} .2680 \mathrm{~T}>\mathrm{A} \\
\text { c. } 3617 \mathrm{G}>\mathrm{T} \\
\text { c. } 4580 \mathrm{G}>\mathrm{A} \\
\text { c. } 4569 \mathrm{G}>\mathrm{A} \\
\text { c. } 3770 \mathrm{G}>\mathrm{T} \\
\text { c. } 1176 \mathrm{delC}\end{array}$ & $\begin{array}{l}\mathrm{S} \\
\mathrm{S} \\
\mathrm{S} \\
\mathrm{S} \\
\mathrm{S} \\
\mathrm{S} \\
\mathrm{S} \\
\mathrm{S} \\
\mathrm{S}\end{array}$ & $\begin{array}{l}c \\
c \\
c \\
c \\
c \\
c \\
c \\
c \\
c\end{array}$ & $\begin{array}{l}\text { Gly1497Cys } \\
\text { His741Asn } \\
\text { Ser894Thr } \\
\text { Gly1206Val } \\
\text { Gly1527Asp } \\
\text { Met1523lle } \\
\text { Gly1257Val } \\
\text { Thr393fs`9 }\end{array}$ & $\begin{array}{l}\text { Moderate } \\
\text { Moderate } \\
\text { Moderate } \\
\text { Moderate } \\
\text { Moderate } \\
\text { Moderate } \\
\text { Moderate } \\
\text { High }\end{array}$ & $\begin{array}{l}\text { ND } \\
\text { Neutral } \\
\text { Neutral } \\
\text { ND } \\
\text { ND } \\
\text { Neutral } \\
\text { ND } \\
\text { ND }\end{array}$ & $\begin{array}{l}\text { TCGA-LIHC } \\
\text { TCGA-LIHC } \\
\text { TCGA-LIHC } \\
\text { TCGA-LIHC } \\
\text { TCGA-LIHC } \\
\text { TCGA-LIHC } \\
\text { TCGA-LIHC } \\
\text { TCGA-LIHC }\end{array}$ & $\begin{array}{l}\text { TCGA } \\
\text { TCGA } \\
\text { TCGA } \\
\text { TCGA } \\
\text { TCGA } \\
\text { TCGA } \\
\text { TCGA } \\
\text { TCGA }\end{array}$ \\
\hline SNAl1 & SNAI1 & $\begin{array}{l}\text { c. }-8 C>A \\
\text { c. }{ }^{*} 305 A>G\end{array}$ & $\begin{array}{l}S \\
S\end{array}$ & $\begin{array}{l}\mathrm{nc} \\
\mathrm{nc}\end{array}$ & $\begin{array}{l}\text { 5'UTR } \\
\text { 3'UTR } \\
\end{array}$ & $\begin{array}{l}\text { Modifier } \\
\text { Modifier }\end{array}$ & $\begin{array}{l}\text { ND } \\
\text { ND }\end{array}$ & $\begin{array}{l}\text { TCGA-LIHC } \\
\text { TCGA-CHOL }\end{array}$ & $\begin{array}{l}\text { TCGA } \\
\text { TCGA } \\
\end{array}$ \\
\hline
\end{tabular}

Data obtained from TCGA and dbEMT databases. Functional consequences are based on VEP (Variant Effect Predictor; https://www. ensembl.org/vep) impact: High means that the variant is supposed to cause a high disruptive impact in the protein, which is likely to cause loss of function; Moderate means that the variant may be not disruptive, but results in a decrease effectiveness of the encoded protein; Modifier is usually referred to non-coding variants, whose impact is difficult to determine, although they can be involved in transcription or splicing changes. HCC: hepatocellular carcinoma; ND: non-determined; TCGA: the cancer genome atlas; TCGA-LIHC: the cancer genome atlas - liver hepatocellular carcinoma; TCGA-CHOL: the cancer genome atlas - cholangiocarcinoma

is still limited. This lack of information is partly due to the fact that most studies carried out so far on PLC chemoresistance have been focused on determining the expression levels of genes involved in MOC as well as their genetic and epigenetic regulation. Therefore, further investigations in this field are needed and highly recommended. Available information suggests that there is high probability of identifying, among genetic variants, both novel biomarkers to predict the failure of the pharmacological treatment and molecular targets to sensitize cancer cells to anticancer drugs, and hence improve the outcome of PLC patients.

\section{DECLARATIONS}

\section{Authors' contributions}

Literature mining: MOC1 (MAP, RAEE), MOC2 (MSM), MOC3 (PSS), MOC4/5 (ASM), MOC6/7 (MSM)

Writing the draft: General aspects (JJGM); MOC1 (MAP, RAEE), MOC2 (MSM), MOC3 (PSS), MOC4/5 (ASM), MOC6/7 (MSM)

Final revison: MAP, ASM, PSS, MSM, RAEE, JJGM 


\section{Availability of data and materials}

Not applicable.

\section{Financial support and sponsorship}

This study was supported by the Biomedical Research Networking Center in Hepatic and Digestive Diseases - CIBERehd (EHD15PI05/2016); the Health Research Fund, Institute of Health Carlos III, Spain (PI16/00598, co-funded by the European Regional Development Fund/European Social Fund, "Investing in your future"); the Spanish Ministry of Economy, Industry and Competitiveness (SAF2016-75197-R); the Regional Government of Castile and Leon (SA063P17); and the AECC Scientific Foundation (2017/2020), Spain. MAP, ASM and PSS were supported by a pre-doctoral contract by "Ministry of Education, Culture and Sports", Spain (BOE-A-2015-9456 and BOE-B-2017-72875). REE was supported by a pre-doctoral contract funded by the "Junta de Castilla y León, Fondo Social Europeo" (EDU/574/2018).

\section{Conflicts of interest}

All authors declared that there are no conflicts of interest.

\section{Ethical approval and consent to participate}

Not applicable.

\section{Consent for publication}

Not applicable.

\section{Copyright}

(C) The Author(s) 2019.

\section{REFERENCES}

1. Bruix J, Sherman M. Management of hepatocellular carcinoma: an update. Hepatology 2011;53:1020-2.

2. Llovet JM, Bruix J. Molecular targeted therapies in hepatocellular carcinoma. Hepatology 2008;48:1312-27.

3. Yao S, Johnson C, Hu Q, Yan L, Liu B, et al. Differences in somatic mutation landscape of hepatocellular carcinoma in Asian American and European American populations. Oncotarget 2016;7:40491-9.

4. Witt-Kehati D, Fridkin A, Alaluf MB, Zemel R, Shlomai A. Inhibition of pMAPK14 overcomes resistance to sorafenib in hepatoma cells with hepatitis b virus. Transl Oncol 2018;11:511-7.

5. EASL. EASL clinical practice guidelines: management of hepatocellular carcinoma. J Hepatol 2018;69:182-236.

6. Llovet JM, Ricci S, Mazzaferro V, Hilgard P, Gane E, et al. Sorafenib in advanced hepatocellular carcinoma. N Engl J Med 2008;359:37890.

7. Bruix J, Qin S, Merle P, Granito A, Huang YH, et al. Regorafenib for patients with hepatocellular carcinoma who progressed on sorafenib treatment (RESORCE): a randomised, double-blind, placebo-controlled, phase 3 trial. Lancet 2017;389:56-66.

8. Jindal A, Thadi A, Shailubhai K. Hepatocellular carcinoma: etiology and current and future drugs. J Clin Exp Hepatol 2019;9:221-32.

9. Macias RIR, Kornek M, Rodrigues PM, Paiva NA, Castro RE, et al. Diagnostic and prognostic biomarkers in cholangiocarcinoma. Liver Int 2019;39 Suppl 1:108-22.

10. Banales JM, Inarrairaegui M, Arbelaiz A, Milkiewicz P, Muntane J, et al. Serum metabolites as diagnostic biomarkers for cholangiocarcinoma, hepatocellular carcinoma, and primary sclerosing cholangitis. Hepatology 2018;doi: 10.1002/hep.30319.

11. Banales JM, Cardinale V, Carpino G, Marzioni M, Andersen JB, et al. Expert consensus document: cholangiocarcinoma: current knowledge and future perspectives consensus statement from the european network for the study of cholangiocarcinoma (ENS-CCA). Nat Rev Gastroenterol Hepatol 2016;13:261-80.

12. Marin JJG, Lozano E, Herraez E, Asensio M, Di Giacomo S, et al. Chemoresistance and chemosensitization in cholangiocarcinoma. Biochim Biophys Acta Mol Basis Dis 2018;1864:1444-53.

13. den Dunnen JT, Dalgleish R, Maglott DR, Hart RK, Greenblatt MS, et al. HGVS recommendations for the description of sequence variants: 2016 Update. Hum Mutat 2016;37:564-9.

14. Sprowl JA, Sparreboom A. Uptake carriers and oncology drug safety. Drug Metab Dispos 2014;42:611-22.

15. Zimmerman EI, Hu S, Roberts JL, Gibson AA, Orwick SJ, et al. Contribution of OATP1B1 and OATP1B3 to the disposition of sorafenib and sorafenib-glucuronide. Clin Cancer Res 2013;19:1458-66.

16. Gong IY, Kim RB. Impact of genetic variation in OATP transporters to drug disposition and response. Drug Metab Pharmacokinet 2013;28:4-18. 
17. Bins S, Lenting A, El Bouazzaoui S, van Doorn L, Oomen-de Hoop E, et al. Polymorphisms in SLCO1B1 and UGT1A1 are associated with sorafenib-induced toxicity. Pharmacogenomics 2016;17:1483-90.

18. Levi F, Karaboue A, Saffroy R, Desterke C, Boige V, et al. Pharmacogenetic determinants of outcomes on triplet hepatic artery infusion and intravenous cetuximab for liver metastases from colorectal cancer (European trial OPTILIV, NCT00852228). Br J Cancer 2017;117:965-73.

19. Sakata T, Anzai N, Kimura T, Miura D, Fukutomi T, et al. Functional analysis of human organic cation transporter OCT3 (SLC22A3) polymorphisms. J Pharmacol Sci 2010;113:263-6.

20. Chen L, Pawlikowski B, Schlessinger A, More SS, Stryke D, et al. Role of organic cation transporter 3 (SLC22A3) and its missense variants in the pharmacologic action of metformin. Pharmacogenet Genomics 2010;20:687-99.

21. Wong AL, Yap HL, Yeo WL, Soong R, Ng SS, et al. Gemcitabine and platinum pathway pharmacogenetics in Asian breast cancer patients. Cancer Genomics Proteomics 2011;8:255-9.

22. Soo RA, Wang LZ, Ng SS, Chong PY, Yong WP, et al. Distribution of gemcitabine pathway genotypes in ethnic Asians and their association with outcome in non-small cell lung cancer patients. Lung Cancer 2009;63:121-7.

23. Joerger M, Burgers JA, Baas P, Doodeman VD, Smits PH, et al. Gene polymorphisms, pharmacokinetics, and hematological toxicity in advanced non-small-cell lung cancer patients receiving cisplatin/gemcitabine. Cancer Chemother Pharmacol 2012;69:25-33.

24. Herraez E, Lozano E, Macias RI, Vaquero J, Bujanda L, et al. Expression of SLC22A1 variants may affect the response of hepatocellular carcinoma and cholangiocarcinoma to sorafenib. Hepatology 2013;58:1065-73.

25. Pongmaneratanakul S, Tanasanvimon S, Pengsuparp T, Areepium N. Prevalence of CTR1 and ERCC1 Polymorphisms and Response of Biliary Tract Cancer to Gemcitabine-Platinum Chemotherapy. Asian Pac J Cancer Prev 2017;18:857-61.

26. Xu X, Duan L, Zhou B, Ma R, Zhou H, et al. Genetic polymorphism of copper transporter protein 1 is related to platinum resistance in Chinese non-small cell lung carcinoma patients. Clin Exp Pharmacol Physiol 2012;39:786-92.

27. Wlcek K, Svoboda M, Riha J, Zakaria S, Olszewski U, et al. The analysis of organic anion transporting polypeptide (OATP) mRNA and protein patterns in primary and metastatic liver cancer. Cancer Biol Ther 2011;11:801-11.

28. Hayer M, Bonisch H, Bruss M. Molecular cloning, functional characterization and genomic organization of four alternatively spliced isoforms of the human organic cation transporter 1 (hOCT1/SLC22A1). Ann Hum Genet 1999;63:473-82.

29. Makhtar SM, Husin A, Baba AA, Ankathil R. Genetic variations in influx transporter gene SLC22A1 are associated with clinical responses to imatinib mesylate among Malaysian chronic myeloid leukaemia patients. J Genet 2018;97:835-42.

30. Cargnin S, Ravegnini G, Soverini S, Angelini S, Terrazzino S. Impact of SLC22A1 and CYP3A5 genotypes on imatinib response in chronic myeloid leukemia: A systematic review and meta-analysis. Pharmacol Res 2018;131:244-54.

31. Koren-Michowitz M, Buzaglo Z, Ribakovsky E, Schwarz M, Pessach I, et al. OCT1 genetic variants are associated with long term outcomes in imatinib treated chronic myeloid leukemia patients. Eur J Haematol 2014;92:283-8.

32. Arimany-Nardi C, Montraveta A, Lee-Verges E, Puente XS, Koepsell H, et al. Human organic cation transporter 1 (hOCT1) as a mediator of bendamustine uptake and cytotoxicity in chronic lymphocytic leukemia (CLL) cells. Pharmacogenomics J 2015;15:363-71.

33. Geier A, Macias RI, Bettinger D, Weiss J, Bantel H, et al. The lack of the organic cation transporter OCT1 at the plasma membrane of tumor cells precludes a positive response to sorafenib in patients with hepatocellular carcinoma. Oncotarget 2017;8:15846-57.

34. Heise M, Lautem A, Knapstein J, Schattenberg JM, Hoppe-Lotichius M, et al. Downregulation of organic cation transporters OCT1 (SLC22A1) and OCT3 (SLC22A3) in human hepatocellular carcinoma and their prognostic significance. BMC Cancer 2012;12:109.

35. Lautem A, Heise M, Grasel A, Hoppe-Lotichius M, Weiler N, et al. Downregulation of organic cation transporter 1 (SLC22A1) is associated with tumor progression and reduced patient survival in human cholangiocellular carcinoma. Int J Oncol 2013;42:1297-304.

36. Guttmann S, Chandhok G, Groba SR, Niemietz C, Sauer V, et al. Organic cation transporter 3 mediates cisplatin and copper crossresistance in hepatoma cells. Oncotarget 2018;9:743-54.

37. Gao PT, Cheng JW, Gong ZJ, Hu B, Sun YF, et al. Low SLC29A1 expression is associated with poor prognosis in patients with hepatocellular carcinoma. Am J Cancer Res 2017;7:2465-77.

38. Chen CF, Hsu EC, Lin KT, Tu PH, Chang HW, et al. Overlapping high-resolution copy number alterations in cancer genomes identified putative cancer genes in hepatocellular carcinoma. Hepatology 2010;52:1690-701.

39. Marin JJ, Romero MR, Briz O. Molecular bases of liver cancer refractoriness to pharmacological treatment. Curr Med Chem 2010;17:70940.

40. Huang WC, Hsieh YL, Hung CM, Chien PH, Chien YF, Chen LC, Tu CY, Chen CH, Hsu SC, Lin YM, Chen YJ. BCRP/ABCG2 inhibition sensitizes hepatocellular carcinoma cells to sorafenib. PLoS One 2013;8:e83627.

41. Agarwal S, Sane R, Ohlfest JR, Elmquist WF. The role of the breast cancer resistance protein (ABCG2) in the distribution of sorafenib to the brain. J Pharmacol Exp Ther 2011;336:223-33.

42. Lagas JS, van Waterschoot RA, Sparidans RW, Wagenaar E, Beijnen JH, et al. Breast cancer resistance protein and P-glycoprotein limit sorafenib brain accumulation. Mol Cancer Ther 2010;9:319-26.

43. Tandia M, Mhiri A, Paule B, Saffroy R, Cailliez V, et al. Correlation between clinical response to sorafenib in hepatocellular carcinoma treatment and polymorphisms of P-glycoprotein (ABCB1) and of breast cancer resistance protein (ABCG2): monocentric study. Cancer Chemother Pharmacol 2017;79:759-66.

44. Marin JJ, Briz O, Perez MJ, Romero MR, Monte MJ. Hepatobiliary transporters in the pharmacology and toxicology of anticancer drugs. Front Biosci (Landmark Ed) 2009;14:4257-80.

45. Ng IO, Liu CL, Fan ST, Ng M. Expression of P-glycoprotein in hepatocellular carcinoma. A determinant of chemotherapy response. Am J Clin Pathol 2000;113:355-63. 
46. Kato A, Miyazaki M, Ambiru S, Yoshitomi H, Ito H, et al. Multidrug resistance gene (MDR-1) expression as a useful prognostic factor in patients with human hepatocellular carcinoma after surgical resection. J Surg Oncol 2001;78:110-5.

47. Cao L, Duchrow M, Windhovel U, Kujath P, Bruch HP, et al. Expression of MDR1 mRNA and encoding P-glycoprotein in archival formalin-fixed paraffin-embedded gall bladder cancer tissues. Eur J Cancer 1998;34:1612-7.

48. Tepsiri N, Chaturat L, Sripa B, Namwat W, Wongkham S, et al. Drug sensitivity and drug resistance profiles of human intrahepatic cholangiocarcinoma cell lines. World J Gastroenterol 2005;11:2748-53.

49. Wolf SJ, Bachtiar M, Wang J, Sim TS, Chong SS, et al. An update on ABCB1 pharmacogenetics: insights from a 3D model into the location and evolutionary conservation of residues corresponding to SNPs associated with drug pharmacokinetics. Pharmacogenomics J 2011;11:315-25.

50. Baldissera VD, de Mattos AA, Coral GP, de Araujo FB, Marroni CA, et al. Evaluation of the C3435T polymorphism in the MDR1 gene in patients with hepatocellular carcinoma. Ann Hepatol 2012;11:899-906.

51. Kimchi-Sarfaty C, Oh JM, Kim IW, Sauna ZE, Calcagno AM, Ambudkar SV, Gottesman MM. A "silent" polymorphism in the MDR1 gene changes substrate specificity. Science 2007;315:525-8.

52. Su Z, Liu G, Fang T, Wang Y, Zhang H, et al. Silencing MRP1-4 genes by RNA interference enhances sensitivity of human hepatoma cells to chemotherapy. Am J Transl Res 2016;8:2790-802.

53. Korita PV, Wakai T, Shirai Y, Matsuda Y, Sakata J, et al. Multidrug resistance-associated protein 2 determines the efficacy of cisplatin in patients with hepatocellular carcinoma. Oncol Rep 2010;23:965-72.

54. Nies AT, Konig J, Pfannschmidt M, Klar E, Hofmann WJ, et al. Expression of the multidrug resistance proteins MRP2 and MRP3 in human hepatocellular carcinoma. Int J Cancer 2001;94:492-9.

55. Wakamatsu T, Nakahashi Y, Hachimine D, Seki T, Okazaki K. The combination of glycyrrhizin and lamivudine can reverse the cisplatin resistance in hepatocellular carcinoma cells through inhibition of multidrug resistance-associated proteins. Int J Oncol 2007;31:1465-72.

56. Martinez-Becerra P, Vaquero J, Romero MR, Lozano E, Anadon C, et al. No correlation between the expression of FXR and genes involved in multidrug resistance phenotype of primary liver tumors. Mol Pharm 2012;9:1693-704.

57. Zhao J, Yu BY, Wang DY, Yang JE. Promoter polymorphism of MRP1 associated with reduced survival in hepatocellular carcinoma. World J Gastroenterol 2010;16:6104-10.

58. Wang Z, Wang B, Tang K, Lee EJ, Chong SS, et al. A functional polymorphism within the MRP1 gene locus identified through its genomic signature of positive selection. Hum Mol Genet 2005;14:2075-87.

59. Wei D, Zhang H, Peng R, Huang C, Bai R. ABCC2 (1249G > A) polymorphism implicates altered transport activity for sorafenib. Xenobiotica 2017;47:1008-14.

60. Daly AK, Aithal GP, Leathart JB, Swainsbury RA, Dang TS, et al. Genetic susceptibility to diclofenac-induced hepatotoxicity: contribution of UGT2B7, CYP2C8, and ABCC2 genotypes. Gastroenterology 2007;132:272-81.

61. Nguyen TD, Markova S, Liu W, Gow JM, Baldwin RM, et al. Functional characterization of ABCC2 promoter polymorphisms and allele-specific expression. Pharmacogenomics J 2013;13:396-402.

62. Lang T, Hitzl M, Burk O, Mornhinweg E, Keil A, et al. Genetic polymorphisms in the multidrug resistance-associated protein 3 (ABCC3, MRP3) gene and relationship to its mRNA and protein expression in human liver. Pharmacogenetics 2004;14:155-64.

63. Edavana VK, Penney RB, Yao-Borengasser A, Starlard-Davenport A, Dhakal IB, et al. Effect of MRP2 and MRP3 Polymorphisms on Anastrozole Glucuronidation and MRP2 and MRP3 Gene Expression in Normal Liver Samples. Int J Cancer Res Mol Mech 2015;1.

64. Eclov RJ, Kim MJ, Chhibber A, Smith RP, Ahituv N, Kroetz DL. ABCG2 regulatory single-nucleotide polymorphisms alter in vivo enhancer activity and expression. Pharmacogenet Genomics 2017;27:454-63.

65. Hoblinger A, Grunhage F, Sauerbruch T, Lammert F. Association of the c.3972C $>$ T variant of the multidrug resistance-associated protein 2 Gene (MRP2/ABCC2) with susceptibility to bile duct cancer. Digestion 2009;80:36-9.

66. Li Z, Xing X, Shan F, Li S, Xiao A, et al. ABCC2-24C > T polymorphism is associated with the response to platinum/5-Fu-based neoadjuvant chemotherapy and better clinical outcomes in advanced gastric cancer patients. Oncotarget 2016;7:55449-57.

67. Han ZG, Tao J, Yu TT, Shan L. Effect of GSTP1 and ABCC2 Polymorphisms on Treatment Response in Patients with Advanced Non-Small Cell Lung Cancer Undergoing Platinum-Based Chemotherapy: A Study in a Chinese Uygur Population. Med Sci Monit 2017;23:1999-2006.

68. Werk AN, Bruckmueller H, Haenisch S, Cascorbi I. Genetic variants may play an important role in mRNA-miRNA interaction: evidence for haplotype-dependent downregulation of ABCC2 (MRP2) by miRNA-379. Pharmacogenet Genomics 2014;24:283-91.

69. Shibayama Y, Nakano K, Maeda H, Taguchi M, Ikeda R, et al. Multidrug resistance protein 2 implicates anticancer drug-resistance to sorafenib. Biol Pharm Bull 2011;34:433-5.

70. Rau S, Autschbach F, Riedel HD, Konig J, Kulaksiz H, et al. Expression of the multidrug resistance proteins MRP2 and MRP3 in human cholangiocellular carcinomas. Eur J Clin Invest 2008;38:134-42.

71. Tomonari T, Takeishi S, Taniguchi T, Tanaka T, Tanaka H, et al. MRP3 as a novel resistance factor for sorafenib in hepatocellular carcinoma. Oncotarget 2016;7:7207-15.

72. Tsukamoto M, Sato S, Satake K, Miyake M, Nakagawa H. Quantitative Evaluation of Drug Resistance Profile of Cells Expressing WildType or Genetic Polymorphic Variants of the Human ABC Transporter ABCC4. Int J Mol Sci 2017;18.

73. Lal S, Sutiman N, Ooi LL, Wong ZW, Wong NS, et al. Pharmacogenetics of ABCB5, ABCC5 and RLIP76 and doxorubicin pharmacokinetics in Asian breast cancer patients. Pharmacogenomics J 2017;17:337-43.

74. Krajinovic M, Elbared J, Drouin S, Bertout L, Rezgui A, et al. Polymorphisms of ABCC5 and NOS3 genes influence doxorubicin cardiotoxicity in survivors of childhood acute lymphoblastic leukemia. Pharmacogenomics J 2016;16:530-5. 
75. Chen YL, Chen PM, Lin PY, Hsiau YT, Chu PY. ABCG2 Overexpression Confers Poor Outcomes in Hepatocellular Carcinoma of Elderly Patients. Anticancer Res 2016;36:2983-8.

76. Marin JJG, Lozano E, Briz O, Al-Abdulla R, Serrano MA, Macias RIR. Molecular Bases of Chemoresistance in Cholangiocarcinoma. Curr Drug Targets 2017;18:889-900.

77. Prasad B, Lai Y, Lin Y, Unadkat JD. Interindividual variability in the hepatic expression of the human breast cancer resistance protein (BCRP/ABCG2): effect of age, sex, and genotype. J Pharm Sci 2013;102:787-93.

78. Ahmed S, Zhou Z, Zhou J, Chen SQ. Pharmacogenomics of Drug Metabolizing Enzymes and Transporters: Relevance to Precision Medicine. Genomics Proteomics Bioinformatics 2016;14:298-313.

79. Zhou J, Wen Q, Li SF, Zhang YF, Gao N, et al. Significant change of cytochrome P450s activities in patients with hepatocellular carcinoma. Oncotarget 2016;7:50612-23.

80. Rochat B. Role of cytochrome P450 activity in the fate of anticancer agents and in drug resistance: focus on tamoxifen, paclitaxel and imatinib metabolism. Clin Pharmacokinet 2005;44:349-66.

81. Zhong JH, Xiang BD, Ma L, You XM, Li LQ, et al. Meta-analysis of microsomal epoxide hydrolase gene polymorphism and risk of hepatocellular carcinoma. PLoS One 2013;8:e57064.

82. Korobkova EA. Effect of natural polyphenols on CYP metabolism: implications for diseases. Chem Res Toxicol 2015;28:1359-90.

83. Zanger UM, Schwab M. Cytochrome P450 enzymes in drug metabolism: regulation of gene expression, enzyme activities, and impact of genetic variation. Pharmacol Ther 2013;138:103-41.

84. Miyoshi Y, Taguchi T, Kim SJ, Tamaki Y, Noguchi S. Prediction of response to docetaxel by immunohistochemical analysis of CYP3A4 expression in human breast cancers. Breast Cancer 2005;12:11-5.

85. Yan T, Lu L, Xie C, Chen J, Peng X, et al. Severely impaired and dysregulated cytochrome p 450 expression and activities in hepatocellular carcinoma: implications for personalized treatment in patients. Mol Cancer Ther 2015;14:2874-86.

86. Fushiya N, Takagi I, Nishino H, Akizuki S, Ohnishi A. Genetic polymorphisms of enzymes related to oral tegafur/uracil therapeutic efficacy in patients with hepatocellular carcinoma. Anticancer Drugs 2013;24:617-22.

87. Sugiyama E, Kaniwa N, Kim SR, Kikura-Hanajiri R, Hasegawa R, et al. Pharmacokinetics of gemcitabine in Japanese cancer patients: the impact of a cytidine deaminase polymorphism. J Clin Oncol 2007;25:32-42.

88. Fujimura T, Takahashi S, Urano T, Kumagai J, Murata T, et al. Expression of cytochrome P450 3A4 and its clinical significance in human prostate cancer. Urology 2009;74:391-7.

89. Oguro A, Sakamoto K, Suzuki S, Imaoka S. Contribution of hydrolase and phosphatase domains in soluble epoxide hydrolase to vascular endothelial growth factor expression and cell growth. Biol Pharm Bull 2009;32:1962-7.

90. Omiecinski CJ, Hassett C, Hosagrahara V. Epoxide hydrolase--polymorphism and role in toxicology. Toxicol Lett 2000;112-113:365-70.

91. Marin JJ, Briz O, Monte MJ, Blazquez AG, Macias RI. Genetic variants in genes involved in mechanisms of chemoresistance to anticancer drugs. Curr Cancer Drug Targets 2012;12:402-38.

92. Hassett C, Aicher L, Sidhu JS, Omiecinski CJ. Human microsomal epoxide hydrolase: genetic polymorphism and functional expression in vitro of amino acid variants. Hum Mol Genet 1994;3:421-8.

93. Jiang W, Lu Z, He Y, Diasio RB. Dihydropyrimidine dehydrogenase activity in hepatocellular carcinoma: implication in 5-fluorouracilbased chemotherapy. Clin Cancer Res 1997;3:395-9.

94. Walko CM, McLeod HL. Will we ever be ready for blood level-guided therapy? J Clin Oncol 2008;26:2078-9.

95. Etienne-Grimaldi MC, Boyer JC, Beroud C, Mbatchi L, van Kuilenburg A, et al. New advances in DPYD genotype and risk of severe toxicity under capecitabine. PLoS One 2017;12:e0175998.

96. Hiratsuka M, Yamashita H, Akai F, Hosono H, Hishinuma E, et al. Genetic polymorphisms of dihydropyrimidinase in a Japanese patient with capecitabine-induced toxicity. PLoS One 2015;10:e0124818.

97. Lin L, Sun J, Tan Y, Li Z, Kong F, et al. Prognostic implication of NQO1 overexpression in hepatocellular carcinoma. Hum Pathol 2017;69:31-7.

98. Buranrat B, Prawan A, Kukongviriyapan U, Kongpetch S, Kukongviriyapan V. Dicoumarol enhances gemcitabine-induced cytotoxicity in high NQO1-expressing cholangiocarcinoma cells. World J Gastroenterol 2010;16:2362-70.

99. Zhou JY, Shi R, Yu HL, Zheng WL, Ma WL. Association of NQO1 Pro187Ser polymorphism with the risks for colorectal cancer and colorectal adenoma: a meta-analysis. Int J Colorectal Dis 2012;27:1123-4.

100. Kolesar JM, Dahlberg SE, Marsh S, McLeod HL, Johnson DH, et al. The NQO1*2/*2 polymorphism is associated with poor overall survival in patients following resection of stages II and IIIa non-small cell lung cancer. Oncol Rep 2011;25:1765-72.

101. Mameri H, Bieche I, Meseure D, Marangoni E, Buhagiar-Labarchede G, et al. Cytidine deaminase deficiency reveals new therapeutic opportunities against cancer. Clin Cancer Res 2017;23:2116-26.

102. Carpi FM, Vincenzetti S, Ubaldi J, Pucciarelli S, Polzonetti V, et al. CDA gene polymorphisms and enzyme activity: genotypephenotype relationship in an Italian-Caucasian population. Pharmacogenomics 2013;14:769-81.

103. Tibaldi C, Giovannetti E, Tiseo M, Leon LG, D'Incecco A, et al. Correlation of cytidine deaminase polymorphisms and activity with clinical outcome in gemcitabine-/platinum-treated advanced non-small-cell lung cancer patients. Ann Oncol 2012;23:670-7.

104. Coulibaly ST, Rossolillo P, Winter F, Kretzschmar FK, Braye M, et al. Potent Sensitisation of Cancer Cells to Anticancer Drugs by a Quadruple Mutant of the Human Deoxycytidine Kinase. PLoS One 2015;10:e0140741.

105. Akhdar H, El Shamieh S, Musso O, Desert R, Joumaa W, et al. The rs3957357C $>$ T SNP in GSTA1 Is Associated with a Higher Risk of Occurrence of Hepatocellular Carcinoma in European Individuals. PLoS One 2016;11:e0167543.

106. Gamage N, Barnett A, Hempel N, Duggleby RG, Windmill KF, et al. Human sulfotransferases and their role in chemical metabolism. 
Toxicol Sci 2006;90:5-22.

107. Brandon EF, Sparidans RW, Meijerman I, Manzanares I, Beijnen JH, et al. In vitro characterization of the biotransformation of thiocoraline, a novel marine anti-cancer drug. Invest New Drugs 2004;22:241-51.

108. Fernandez-Santander A, Gaibar M, Novillo A, Romero-Lorca A, Rubio M, et al. Relationship between genotypes Sult1a2 and Cyp2d6 and tamoxifen metabolism in breast cancer patients. PLoS One 2013;8:e70183.

109. Lu L, Zhou J, Shi J, Peng XJ, Qi XX, et al. Drug-metabolizing activity, protein and gene expression of udp-glucuronosyltransferases are significantly altered in hepatocellular carcinoma patients. PLoS One 2015;10:e0127524.

110. Ye L, Yang X, Guo E, Chen W, Lu L, et al. Sorafenib metabolism is significantly altered in the liver tumor tissue of hepatocellular carcinoma patient. PLoS One 2014;9:e96664.

111. Hu DG, Mackenzie PI, Lu L, Meech R, McKinnon RA. Induction of human UDP-Glucuronosyltransferase $2 \mathrm{~B} 7$ gene expression by cytotoxic anticancer drugs in liver cancer HepG2 cells. Drug Metab Dispos 2015;43:660-8.

112. Zahreddine HA, Borden KL. Molecular pathways: GLI1-induced drug glucuronidation in resistant cancer cells. Clin Cancer Res 2015;21:2207-10.

113. Marin JJ, Romero MR, Martinez-Becerra P, Herraez E, Briz O. Overview of the molecular bases of resistance to chemotherapy in liver and gastrointestinal tumours. Curr Mol Med 2009;9:1108-29.

114. Zheng YB, Zhan MX, Zhao W, Liu B, Huang JW, et al. The relationship of kinase insert domain receptor gene polymorphisms and clinical outcome in advanced hepatocellular carcinoma patients treated with sorafenib. Med Oncol 2014;31:209.

115. Jain L, Sissung TM, Danesi R, Kohn EC, Dahut WL, et al. Hypertension and hand-foot skin reactions related to VEGFR2 genotype and improved clinical outcome following bevacizumab and sorafenib. J Exp Clin Cancer Res 2010;29:95.

116. Hansen TF, Garm Spindler KL, Andersen RF, Lindebjerg J, Brandslund I, et al. The predictive value of genetic variations in the vascular endothelial growth factor A gene in metastatic colorectal cancer. Pharmacogenomics J 2011;11:53-60.

117. Orlandi P, Fontana A, Fioravanti A, Di Desidero T, Galli L, et al. VEGF-A polymorphisms predict progression-free survival among advanced castration-resistant prostate cancer patients treated with metronomic cyclophosphamide. Br J Cancer 2013;109:957-64.

118. Scartozzi M, Faloppi L, Svegliati Baroni G, Loretelli C, Piscaglia F, et al. VEGF and VEGFR genotyping in the prediction of clinical outcome for HCC patients receiving sorafenib: the ALICE-1 study. Int J Cancer 2014;135:1247-56.

119. Schulze K, Imbeaud S, Letouze E, Alexandrov LB, Calderaro J, et al. Exome sequencing of hepatocellular carcinomas identifies new mutational signatures and potential therapeutic targets. Nat Genet 2015;47:505-11.

120. Robertson S, Hyder O, Dodson R, Nayar SK, Poling J, et al. The frequency of KRAS and BRAF mutations in intrahepatic cholangiocarcinomas and their correlation with clinical outcome. Hum Pathol 2013;44:2768-73.

121. Angkathunyakul N, Rosini F, Heaton N, Foskett P, Quaglia A. BRAF V600E mutation in biliary proliferations associated with alpha1antitrypsin deficiency. Histopathology 2017;70:485-91.

122. Dow M, Pyke RM, Tsui BY, Alexandrov LB, Nakagawa H, et al. Integrative genomic analysis of mouse and human hepatocellular carcinoma. Proc Natl Acad Sci U S A 2018;115:E9879-E88.

123. Yamamoto M, Tanaka H, Xin B, Nishikawa Y, Yamazaki K, et al. Role of the BrafV637E mutation in hepatocarcinogenesis induced by treatment with diethylnitrosamine in neonatal B6C3F1 mice. Mol Carcinog 2017;56:478-88.

124. Crystal AS, Shaw AT, Sequist LV, Friboulet L, Niederst MJ, et al. Patient-derived models of acquired resistance can identify effective drug combinations for cancer. Science 2014;346:1480-6.

125. Bean J, Brennan C, Shih JY, Riely G, Viale A, et al. MET amplification occurs with or without T790M mutations in EGFR mutant lung tumors with acquired resistance to gefitinib or erlotinib. Proc Natl Acad Sci U S A 2007;104:20932-7.

126. Dong LQ, Shi Y, Ma LJ, Yang LX, Wang XY, et al. Spatial and temporal clonal evolution of intrahepatic cholangiocarcinoma. J Hepatol 2018;69:89-98.

127. Rad R, Cadinanos J, Rad L, Varela I, Strong A, et al. A genetic progression model of Braf(V600E)-induced intestinal tumorigenesis reveals targets for therapeutic intervention. Cancer Cell 2013;24:15-29.

128. Aboussekhra A, Biggerstaff M, Shivji MK, Vilpo JA, Moncollin V, et al. Mammalian DNA nucleotide excision repair reconstituted with purified protein components. Cell 1995;80:859-68.

129. Zhou W, Gurubhagavatula S, Liu G, Park S, Neuberg DS, et al. Excision repair cross-complementation group 1 polymorphism predicts overall survival in advanced non-small cell lung cancer patients treated with platinum-based chemotherapy. Clin Cancer Res 2004;10:4939-43.

130. Gurubhagavatula S, Liu G, Park S, Zhou W, Su L, et al. XPD and XRCC1 genetic polymorphisms are prognostic factors in advanced non-small-cell lung cancer patients treated with platinum chemotherapy. J Clin Oncol 2004;22:2594-601.

131. Yang Z, Zhao J. Effect of APE1 and XRCC1 gene polymorphism on susceptibility to hepatocellular carcinoma and sensitivity to cisplatin. Int J Clin Exp Med 2015;8:9931-6.

132. Golan T, Raitses-Gurevich M, Kelley RK, Bocobo AG, Borgida A, et al. Overall Survival and Clinical Characteristics of BRCAAssociated Cholangiocarcinoma: A Multicenter Retrospective Study. Oncologist 2017;22:804-10.

133. Wardell CP, Fujita M, Yamada T, Simbolo M, Fassan M, et al. Genomic characterization of biliary tract cancers identifies driver genes and predisposing mutations. J Hepatol 2018;68:959-69.

134. Zimmer AS, Gillard M, Lipkowitz S, Lee JM. Update on PARP Inhibitors in Breast Cancer. Curr Treat Options Oncol 2018;19:21.

135. Ueda S, Shirabe K, Morita K, Umeda K, Kayashima H, et al. Evaluation of ERCC1 expression for cisplatin sensitivity in human hepatocellular carcinoma. Ann Surg Oncol 2011;18:1204-11.

136. Fautrel A, Andrieux L, Musso O, Boudjema K, Guillouzo A, et al. Overexpression of the two nucleotide excision repair genes ERCC1 
and XPC in human hepatocellular carcinoma. J Hepatol 2005;43:288-93.

137. Van Allen EM, Mouw KW, Kim P, Iyer G, Wagle N, et al. Somatic ERCC2 mutations correlate with cisplatin sensitivity in muscleinvasive urothelial carcinoma. Cancer Discov 2014;4:1140-53.

138. Sishc BJ, Davis AJ. The role of the core non-homologous end joining factors in carcinogenesis and cancer. Cancers (Basel) 2017;9:E81.

139. Yang S, Wang XQ. XLF-mediated NHEJ activity in hepatocellular carcinoma therapy resistance. BMC Cancer 2017;17:344.

140. Schulze K, Nault JC, Villanueva A. Genetic profiling of hepatocellular carcinoma using next-generation sequencing. J Hepatol 2016;65:1031-42.

141. Bullock AN, Fersht AR. Rescuing the function of mutant p53. Nat Rev Cancer 2001;1:68-76.

142. Ye S, Zhao XY, Hu XG, Li T, Xu QR, et al. TP53 and RET may serve as biomarkers of prognostic evaluation and targeted therapy in hepatocellular carcinoma. Oncol Rep 2017;37:2215-26.

143. Woo HG, Wang XW, Budhu A, Kim YH, Kwon SM, et al. Association of TP53 mutations with stem cell-like gene expression and survival of patients with hepatocellular carcinoma. Gastroenterology 2011;140:1063-70.

144. Chan KT, Lung ML. Mutant p53 expression enhances drug resistance in a hepatocellular carcinoma cell line. Cancer Chemother Pharmacol 2004;53:519-26.

145. Melino G. p63 is a suppressor of tumorigenesis and metastasis interacting with mutant p53. Cell Death Differ 2011;18:1487-99.

146. Melino G, Bernassola F, Ranalli M, Yee K, Zong WX, et al. p73 Induces apoptosis via PUMA transactivation and Bax mitochondrial translocation. J Biol Chem 2004;279:8076-83.

147. Gonzalez R, De la Rosa AJ, Rufini A, Rodriguez-Hernandez MA, Navarro-Villaran E, et al. Role of p63 and p73 isoforms on the cell death in patients with hepatocellular carcinoma submitted to orthotopic liver transplantation. PLoS One 2017;12:e0174326.

148. Mundt HM, Stremmel W, Melino G, Krammer PH, Schilling T, et al. Dominant negative (DeltaN) p63alpha induces drug resistance in hepatocellular carcinoma by interference with apoptosis signaling pathways. Biochem Biophys Res Commun 2010;396:335-41.

149. Kayhanian H, Smyth EC, Braconi C. Emerging molecular targets and therapy for cholangiocarcinoma. World J Gastrointest Oncol 2017;9:268-80.

150. Nutthasirikul N, Limpaiboon T, Leelayuwat C, Patrakitkomjorn S, Jearanaikoon P. Ratio disruption of the 133p53 and TAp53 isoform equilibrium correlates with poor clinical outcome in intrahepatic cholangiocarcinoma. Int J Oncol 2013;42:1181-8.

151. Nutthasirikul N, Hahnvajanawong C, Techasen A, Limpaiboon T, Leelayuwat C, et al. Targeting the 133p53 isoform can restore chemosensitivity in 5-fluorouracil-resistant cholangiocarcinoma cells. Int J Oncol 2015;47:2153-64.

152. Ahn DH, Javle M, Ahn CW, Jain A, Mikhail S, et al. Next-generation sequencing survey of biliary tract cancer reveals the association between tumor somatic variants and chemotherapy resistance. Cancer 2016;122:3657-66.

153. Namwat N, Amimanan P, Loilome W, Jearanaikoon P, Sripa B, et al. Characterization of 5-fluorouracil-resistant cholangiocarcinoma cell lines. Chemotherapy 2008;54:343-51.

154. Soung YH, Lee JW, Kim SY, Sung YJ, Park WS, et al. Caspase-8 gene is frequently inactivated by the frameshift somatic mutation 1225_1226delTG in hepatocellular carcinomas. Oncogene 2005;24:141-7.

155. Ahn SM, Jang SJ, Shim JH, Kim D, Hong SM, et al. Genomic portrait of resectable hepatocellular carcinomas: implications of RB1 and FGF19 aberrations for patient stratification. Hepatology 2014;60:1972-82.

156. Wattanawongdon W, Hahnvajanawong C, Namwat N, Kanchanawat S, Boonmars T, Jearanaikoon P, et al. Establishment and characterization of gemcitabine-resistant human cholangiocarcinoma cell lines with multidrug resistance and enhanced invasiveness. Int J Oncol 2015;47:398-410.

157. Wang Z, Sheng YY, Gao XM, Wang CQ, Wang XY, et al. Beta-catenin mutation is correlated with a favorable prognosis in patients with hepatocellular carcinoma. Mol Clin Oncol 2015;3:936-40.

158. Hsu HC, Jeng YM, Mao TL, Chu JS, Lai PL, et al. Beta-catenin mutations are associated with a subset of low-stage hepatocellular carcinoma negative for hepatitis B virus and with favorable prognosis. Am J Pathol 2000;157:763-70.

159. Nhieu JT, Renard CA, Wei Y, Cherqui D, Zafrani ES, et al. Nuclear accumulation of mutated beta-catenin in hepatocellular carcinoma is associated with increased cell proliferation. Am J Pathol 1999;155:703-10.

160. Inagawa S, Itabashi M, Adachi S, Kawamoto T, Hori M, et al. Expression and prognostic roles of beta-catenin in hepatocellular carcinoma: correlation with tumor progression and postoperative survival. Clin Cancer Res 2002;8:450-6.

161. Kan Z, Zheng H, Liu X, Li S, Barber TD, et al. Whole-genome sequencing identifies recurrent mutations in hepatocellular carcinoma. Genome Res 2013;23:1422-33.

162. Yokoyama M, Ohnishi H, Ohtsuka K, Matsushima S, Ohkura Y, et al. KRAS mutation as a potential prognostic biomarker of biliary tract cancers. Jpn Clin Med 2016;7:33-9.

163. Yeung Y, Lau DK, Chionh F, Tran H, Tse JWT, et al. K-Ras mutation and amplification status is predictive of resistance and high basal pAKT is predictive of sensitivity to everolimus in biliary tract cancer cell lines. Mol Oncol 2017;11:1130-42.

164. Yu C, Wang X, Huang L, Tong Y, Chen L, et al. Deciphering the spectrum of mitochondrial DNA mutations in hepatocellular carcinoma using high-throughput sequencing. Gene Expr 2018;18:125-34.

165. Kawamura N, Nagai H, Bando K, Koyama M, Matsumoto S, et al. PTEN/MMAC1 mutations in hepatocellular carcinomas: somatic inactivation of both alleles in tumors. Jpn J Cancer Res 1999;90:413-8.

166. Fujiwara Y, Hoon DS, Yamada T, Umeshita K, Gotoh M, et al. PTEN / MMAC1 mutation and frequent loss of heterozygosity identified in chromosome 10q in a subset of hepatocellular carcinomas. Jpn J Cancer Res 2000;91:287-92.

167. Ho DWH, Chan LK, Chiu YT, Xu IMJ, Poon RTP, et al. TSC1/2 mutations define a molecular subset of HCC with aggressive behaviour and treatment implication. Gut 2017;66:1496-506. 
168. Galmarini CM, Bouchet BP, Audoynaud C, Lamblot C, Falette N, et al. A p21/WAF1 mutation favors the appearance of drug resistance to paclitaxel in human noncancerous epithelial mammary cells. Int J Cancer 2006;119:60-6.

169. Fulda S. Tumor resistance to apoptosis. Int J Cancer 2009;124:511-5.

170. Li M, Wu XM, Gao J, Yang F, Zhang CL, et al. Mutations in the P10 region of procaspase-8 lead to chemotherapy resistance in acute myeloid leukemia by impairing procaspase-8 dimerization. Cell Death Dis 2018;9:516.

171. Zhou L, Huang Y, Li J, Wang Z. The mTOR pathway is associated with the poor prognosis of human hepatocellular carcinoma. Med Oncol 2010;27:255-61.

172. Tanaka Y, Kanai F, Tada M, Asaoka Y, Guleng B, et al. Absence of PIK3CA hotspot mutations in hepatocellular carcinoma in Japanese patients. Oncogene 2006;25:2950-2.

173. Lee JW, Soung YH, Kim SY, Lee HW, Park WS, et al. PIK3CA gene is frequently mutated in breast carcinomas and hepatocellular carcinomas. Oncogene 2005;24:1477-80.

174. Kudo Y, Tanaka Y, Tateishi K, Yamamoto K, Yamamoto S, et al. Altered composition of fatty acids exacerbates hepatotumorigenesis during activation of the phosphatidylinositol 3-kinase pathway. J Hepatol 2011;55:1400-8.

175. Dogruluk T, Tsang YH, Espitia M, Chen F, Chen T, et al. Identification of Variant-Specific Functions of PIK3CA by Rapid Phenotyping of Rare Mutations. Cancer Res 2015;75:5341-54.

176. Chen KF, Chen HL, Tai WT, Feng WC, Hsu CH, et al. Activation of phosphatidylinositol 3-kinase/Akt signaling pathway mediates acquired resistance to sorafenib in hepatocellular carcinoma cells. J Pharmacol Exp Ther 2011;337:155-61.

177. Wang L, Wang WL, Zhang Y, Guo SP, Zhang J, et al. Epigenetic and genetic alterations of PTEN in hepatocellular carcinoma. Hepatol Res 2007;37:389-96.

178. Zhou Q, Lui VW, Yeo W. Targeting the PI3K/Akt/mTOR pathway in hepatocellular carcinoma. Future Oncol 2011;7:1149-67.

179. Huynh H, Hao HX, Chan SL, Chen D, Ong R, et al. Loss of Tuberous Sclerosis Complex 2 (TSC2) Is Frequent in Hepatocellular Carcinoma and Predicts Response to mTORC1 Inhibitor Everolimus. Mol Cancer Ther 2015;14:1224-35.

180. Tai WT, Cheng AL, Shiau CW, Liu CY, Ko CH, et al. Dovitinib induces apoptosis and overcomes sorafenib resistance in hepatocellular carcinoma through SHP-1-mediated inhibition of STAT3. Mol Cancer Ther 2012;11:452-63.

181. Yang S, Luo C, Gu Q, Xu Q, Wang G, et al. Activating JAK1 mutation may predict the sensitivity of JAK-STAT inhibition in hepatocellular carcinoma. Oncotarget 2016;7:5461-9.

182. Rao CV, Asch AS, Yamada HY. Frequently mutated genes/pathways and genomic instability as prevention targets in liver cancer. Carcinogenesis 2017;38:2-11.

183. Ou DL, Lee BS, Chang YC, Lin LI, Liou JY, et al. Potentiating the efficacy of molecular targeted therapy for hepatocellular carcinoma by inhibiting the insulin-like growth factor pathway. PLoS One 2013;8:e66589.

184. Tovar V, Cornella H, Moeini A, Vidal S, Hoshida Y, et al. Tumour initiating cells and IGF/FGF signalling contribute to sorafenib resistance in hepatocellular carcinoma. Gut 2017;66:530-40.

185. Lee YI, Han YJ, Lee SY, Park SK, Park YJ, et al. Activation of insulin-like growth factor II signaling by mutant type p53: physiological implications for potentiation of IGF-II signaling by p53 mutant 249. Mol Cell Endocrinol 2003;203:51-63.

186. Huang WC, Tsai CC, Chan CC. Mutation analysis and copy number changes of KRAS and BRAF genes in Taiwanese cases of biliary tract cholangiocarcinoma. J Formos Med Assoc 2017;116:464-8.

187. Xu RF, Sun JP, Zhang SR, Zhu GS, Li LB, et al. KRAS and PIK3CA but not BRAF genes are frequently mutated in Chinese cholangiocarcinoma patients. Biomed Pharmacother 2011;65:22-6.

188. Scheffzek K, Ahmadian MR, Kabsch W, Wiesmuller L, Lautwein A, et al. The Ras-RasGAP complex: structural basis for GTPase activation and its loss in oncogenic Ras mutants. Science 1997;277:333-8.

189. Rashid A, Ueki T, Gao YT, Houlihan PS, Wallace C, et al. K-ras mutation, p53 overexpression, and microsatellite instability in biliary tract cancers: a population-based study in China. Clin Cancer Res 2002;8:3156-63.

190. Yin PH, Wu CC, Lin JC, Chi CW, Wei YH, et al. Somatic mutations of mitochondrial genome in hepatocellular carcinoma. Mitochondrion 2010;10:174-82.

191. Levine B, Kroemer G. Autophagy in the pathogenesis of disease. Cell 2008;132:27-42.

192. Sui X, Chen R, Wang Z, Huang Z, Kong N, et al. Autophagy and chemotherapy resistance: a promising therapeutic target for cancer treatment. Cell Death Dis 2013;4:e838.

193. Hanahan D, Weinberg RA. Hallmarks of cancer: the next generation. Cell 2011;144:646-74.

194. Leyva-Illades D, McMillin M, Quinn M, Demorrow S. Cholangiocarcinoma pathogenesis: Role of the tumor microenvironment. Transl Gastrointest Cancer 2012;1:71-80.

195. Yamada S, Okumura N, Wei L, Fuchs BC, Fujii T, et al. Epithelial to mesenchymal transition is associated with shorter disease-free survival in hepatocellular carcinoma. Ann Surg Oncol 2014;21:3882-90.

196. Giannelli G, Koudelkova P, Dituri F, Mikulits W. Role of epithelial to mesenchymal transition in hepatocellular carcinoma. J Hepatol 2016;65:798-808.

197. Kong P, Christia P, Saxena A, Su Y, Frangogiannis NG. Lack of specificity of fibroblast-specific protein 1 in cardiac remodeling and fibrosis. Am J Physiol Heart Circ Physiol 2013;305:H1363-72.

198. Kremmer E, Thierfelder S, Kummer U, Lederer R, Mysliwietz J. Neutralization of immunosuppression by antibodies against variable as well as constant regions of monoclonal anti-Thy-1 xenoantibodies and their ability to be suppressed by initial $\mathrm{T}$ cell depletion. Transplantation 1989;47:641-6.

199. Vaquero J, Guedj N, Claperon A, Nguyen Ho-Bouldoires TH, Paradis V, et al. Epithelial-mesenchymal transition in cholangiocarcinoma: 
from clinical evidence to regulatory networks. J Hepatol 2017;66:424-41.

200. Araki K, Shimura T, Suzuki H, Tsutsumi S, Wada W, et al. E/N-cadherin switch mediates cancer progression via TGF-beta-induced epithelial-to-mesenchymal transition in extrahepatic cholangiocarcinoma. Br J Cancer 2011;105:1885-93.

201. Sheng L, Zhang S, Xu H. Effect of slug-mediated down-regulation of e-cadherin on invasiveness and metastasis of anaplastic thyroid cancer cells. Med Sci Monit 2017;23:138-43.

202. Endo K, Ashida K, Miyake N, Terada T. E-cadherin gene mutations in human intrahepatic cholangiocarcinoma. J Pathol 2001;193:310-7.

203. Lee S, Kim WH, Jung HY, Yang MH, Kang GH. Aberrant CpG island methylation of multiple genes in intrahepatic cholangiocarcinoma. Am J Pathol 2002;161:1015-22.

204. Yang B, House MG, Guo M, Herman JG, Clark DP. Promoter methylation profiles of tumor suppressor genes in intrahepatic and extrahepatic cholangiocarcinoma. Mod Pathol 2005;18:412-20.

205. Yamada D, Kobayashi S, Wada H, Kawamoto K, Marubashi S, et al. Role of crosstalk between interleukin-6 and transforming growth factor-beta 1 in epithelial-mesenchymal transition and chemoresistance in biliary tract cancer. Eur J Cancer 2013;49:1725-40.

206. Zhang Y, Zeng S, Ma J, Deng G, Qu Y, et al. Nestin overexpression in hepatocellular carcinoma associates with epithelial-mesenchymal transition and chemoresistance. J Exp Clin Cancer Res 2016;35:111.

207. Warzecha CC, Jiang P, Amirikian K, Dittmar KA, Lu H, et al. An ESRP-regulated splicing programme is abrogated during the epithelialmesenchymal transition. EMBO J 2010;29:3286-300.

208. Brown RL, Reinke LM, Damerow MS, Perez D, Chodosh LA, et al. CD44 splice isoform switching in human and mouse epithelium is essential for epithelial-mesenchymal transition and breast cancer progression. J Clin Invest 2011;121:1064-74.

209. Shapiro IM, Cheng AW, Flytzanis NC, Balsamo M, Condeelis JS, et al. An EMT-driven alternative splicing program occurs in human breast cancer and modulates cellular phenotype. PLoS Genet 2011;7:e1002218. 